\title{
The Degree Academic and Administrative Leaders Practice Knowledge Management at Al Al-Bayt University in the Hashemite Kingdom of Jordan
}

\author{
Mohammad Aboud AL- Harahsheh \\ Faculty of Educational Sciences \\ AL Al-Bayt University \\ dr_harah@yahoo.com
}

\author{
Ghezail Saeed Dalmouk Al Dosar \\ Ministry of Education \\ State of Kuwait \\ miis_q8@yahoo.com
}

\begin{abstract}
:
The study aims to know the degree of academic and administrative leadership practice knowledge management at Al Al-Bayt University in the Hashemite Kingdom of Jordan, and the effect of variables (gender, educational qualification, years of experience, stage, and job title) on that. The study sample consists of (375) faculty and administrative members. To achieve the goals of the study, a tool was built to measure the degree of knowledge management practice, which consists of (37) items distributed into four areas, namely (knowledge organization, knowledge generation, knowledge sharing, and application of knowledge). Validity and reliability were verified, and the descriptive survey method was used. The results of the study show that the degree of academic and administrative leaders' practice of knowledge management at Al Al-Bayt University in the Hashemite Kingdom of Jordan, from the viewpoint of their colleagues, came with a medium degree in all fields. The results also show that there were statistically significant differences between the averages of the responses of the study sample individuals due to the gender variable, and the differences are in favor of males in all fields. The results also show that there are statistically significant differences attributable to the variable of the academic qualification in the fields of sharing and applying knowledge, and the differences are in favor of the qualification of (Bachelor). The presence of statistically significant differences attributable to the variable of years of experience in the areas of knowledge sharing and application; the absence of statistically significant differences is attributable to the job title in all fields. In light of the results, the study presents a set of recommendations, the most important of which are training academic and administrative leaders on the application of knowledge management; training academic staff on teaching and evaluation methods that help to raise the levels of performance in the educational learning process.
\end{abstract}

Keywords: Knowledge Management, Academic Leaders, Administrative Leaders, Al Al-Bayt University, Jordan. 


\section{درجة ممارسة القادة الأكاديميين والإداريين في جامعة آل البيت في المملكة الأردنية الهاشمية لإدارة المعرفة}

\author{
غزيل سعيد دلموك الدوسري

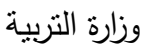 \\ الكويت
}

miis_q8@yahoo.com

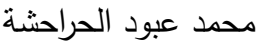 \\ كلبة العلوم التزبوية \\ جامعة آل البيت
}

dr_harah@yahoo.com

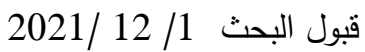

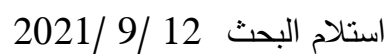

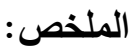

هدفت الدراسة إلى تعرف درجة ممارسة القادة الأكاديميين والإداريين في جامعة آل البيت في المملكة الأردنية الهاشمية لإدارة المعرفة، وأثر

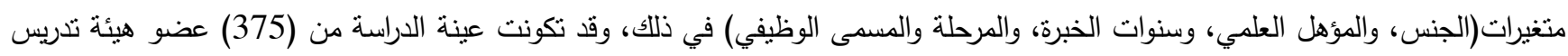

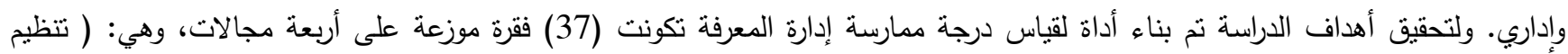

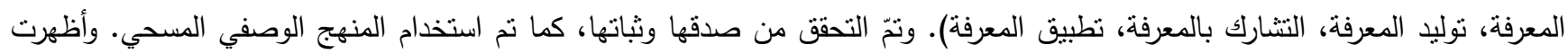

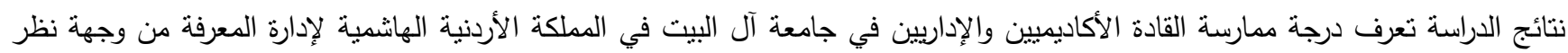

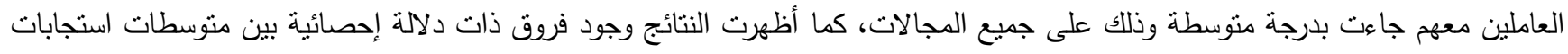

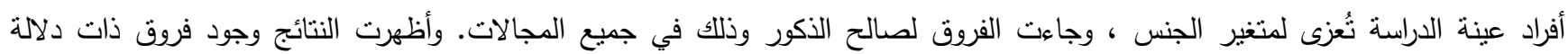
إحصائية تُعزى لمتغير المؤهل العلمي في مجالي التشارك في المعرفة وتطبيق المعرفة ، وجاءت الفروق لصالح المؤهل(البكالوريوس). وأظهرت

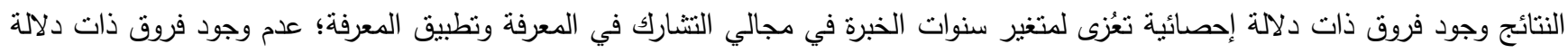

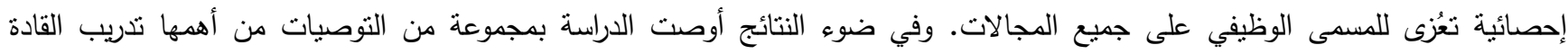

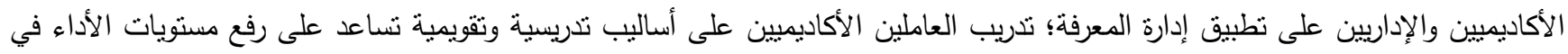

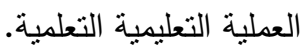

الكلمات المفتاحية: إدارة المعرفة، القادة الأكاديميون، القادة الإداريون، جامعة آل البيت، الأردن.

في وضـع تتافسـي متقدم تُحسافظ من خلالـه المؤسســة على ديمومنها،

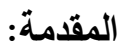

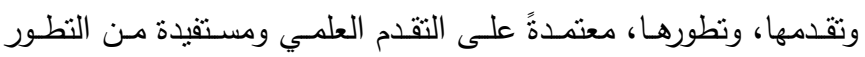

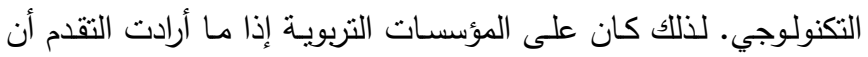
تُخخل إدارة المعرفة في مؤسساتها وهياكلها الإدارية وتُعد أفرادها إعداداً

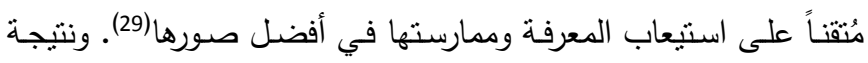

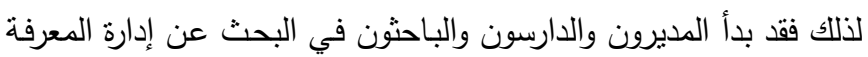
التي نسـاعدهم في مواجهة تحديات العصر ، وإيجاد الحلـول السليمة للمشاكل التي تواجهمج(22). ويعود الاهنمام المتزايد بإدارة المعرفة من قبل فئل مختلف المؤسسات ، وتبني وتطبيق إدارة المعرفة يؤدي إلى تحقيق العديد

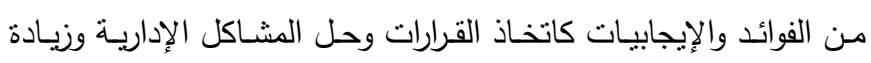
الكفاءة والفعالية، وتحسين جودة المخرجات وزيادة الإنتاجيـة وتحسين

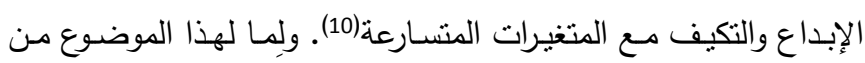

يعتمد العالم في هذا العصر على إدارة المعرفة والسرعة في

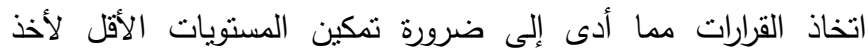
الصلاحيات اللازمة لاتخاذ القرارات المناسبة في الزمان والمكان

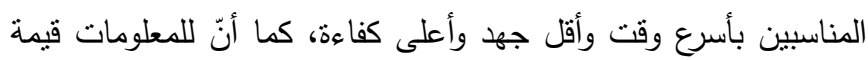

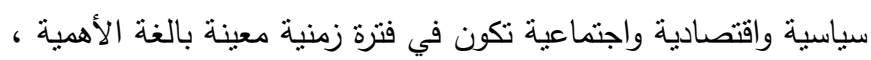

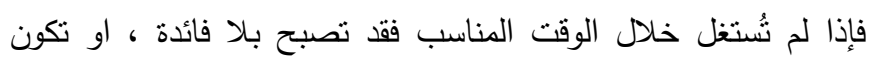
قيمتها المادية أو المعنوية أقل مما لو استُغلت في الوقت المناسب.

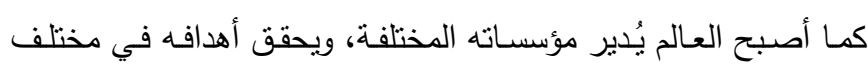
المجالات، الاقتصادية والتربوية والاجتماعية، معتمداً على إدارة المعرفة الهائة

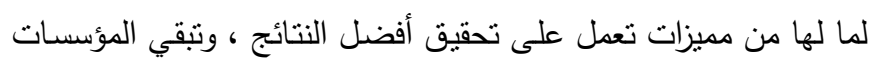


أسئلة الدراسة:

أجابت الدراسة عن الأسئلة الآتية:

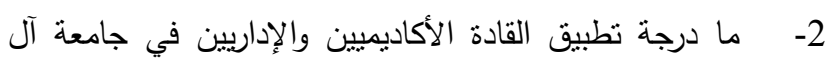

البيت لإدارة المعرفة من وجهة نظر العاملين فيها؟

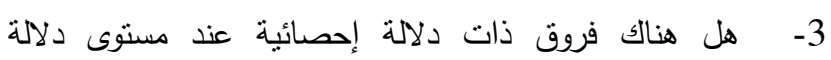

(a $\leq 0.05)$

تطبيق القادة الأكاديميين والإداريين في جامعة آل البيت لإدابـ البارة

المعرفة من وجهة نظر العاملين فيها تعُزى لمتغير (الجنس والمؤهل

العلمي وسنوات الخبرة والمسمى الوظيفي)؟ نها؟

أهداف الدراسة:

هدفت هذه الدراسة إلى تعرّت واقع درجة ممارسة القادة الأكاديميين والإداريين في جامعة آل البيت في المملكة الأردنية الهاشمية لإدارة

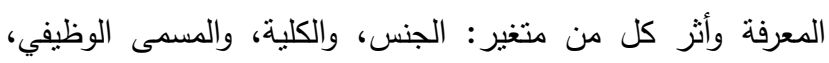
والرتبة.

أهمية الدراسة: والتة

يمكن صياغة أهية الدراسة في النقاط الآثية:

1- تتبع أهمية الدراسة من أهمية الموضوع ذاته بتتاولها موضوعاً

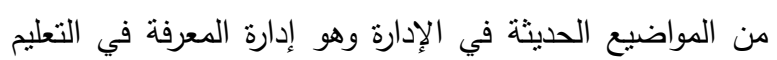
العالي.

2- يؤمل أن بستقفي من هذه الدراسة القادة الأكاديميون والإداريون

والعاملون معهم في جامعة آل البيت.

3- - يؤمل أن يفاد من نتائجها للقادة الأكاديميين والإداريين والعاملين

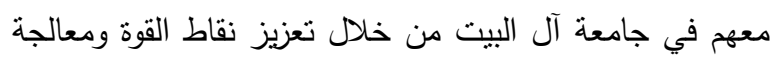

$$
\text { نقاط الضعف إن وجدت. }
$$

4- يؤمل أن يفيد من نتائج هذه الدراسة صناع القرار الأكاديمي

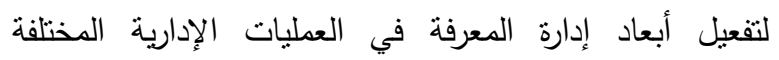

للوصول إلى قرارات صائبة.

التعريفات الاصطلاحية والإجرائية:

استخدم الباحثان في هذه الدراسة عدة مصطلحات نرى ضرانه ضرورة

$$
\text { تعريفها وهي على النحو النالي : الناحثي }
$$

المعرفة (Knowledge): تعرف "بأنها مزيج من الخبات الخبرات

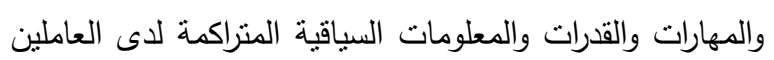

ولدى المنظمة، وهي أنواع مختلفة تثمل المعرفة الضمنية

$$
\text { والواضحة ومعرفة- كيف"(22). }
$$

إدارة المعرفة (Knowledge Management) : "'"هي

العمليات والنشاطات التي نساعد المنظمة على توليد والحصول على المعرفة من حيث اختيارها، تتظيمها واستخدامها ونشرها،
أهيـة بالغة فانـه يجب الاهتمـام بمنبع إدارة المعرفة الذي يُخرّج القادة

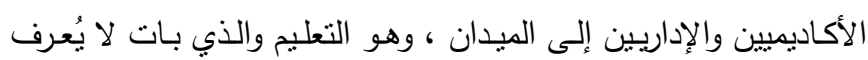

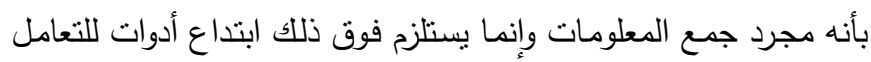
مـع المعلومات ثُكسبها على الدوام أبعادا جديدة ومقُدرة تأثيراً أكبر (19).

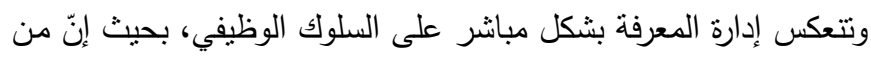

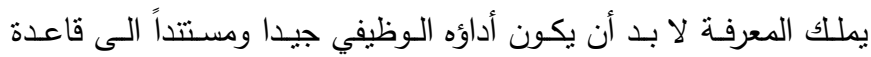

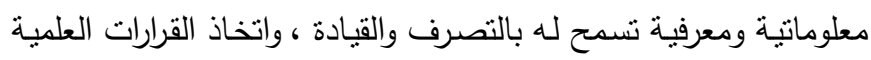

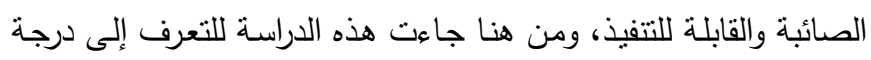

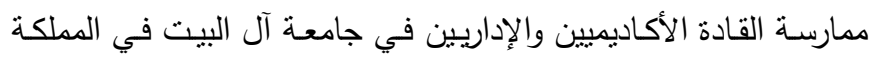
الأردنية الهاشمية لإدارة المعرفة من وجهة نظر العاملين فيها.

مُشيكلة الاراسة:

نظراً لأهمية إدارة المعرفة في منظمات الأعمال والمؤسسات الخدمية وخاصة مؤسسات التعليم العالي وأهميتها في نطوير أدائها وأداء

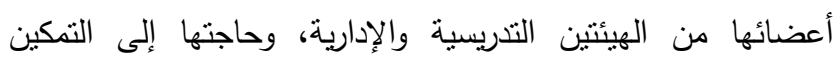

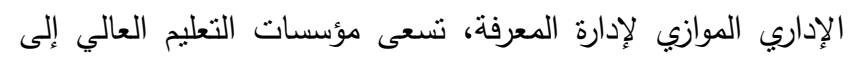

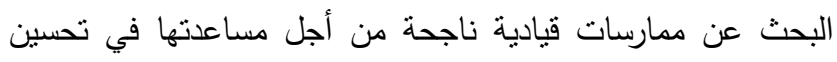

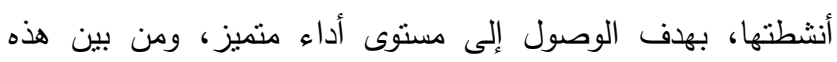

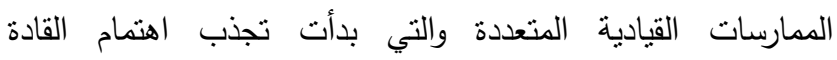
الأكاديميين والإداريين إدارةُ المعرفة. وتُعدّ الجامعة من أهم المؤسسات الملاعمة لتبني إدارة المعرفة(34).

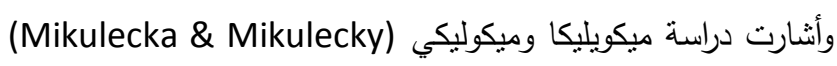
إلى أنّ الجامعات هي مؤسسات لإدارة المعرفة والاستخدام الفعال لإدارة

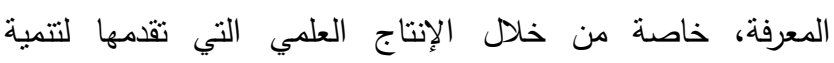

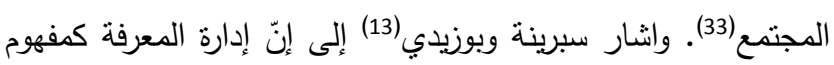

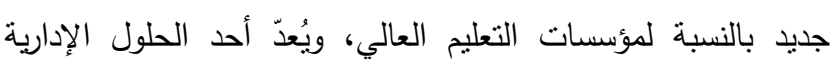

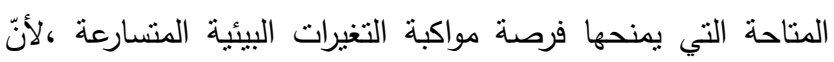

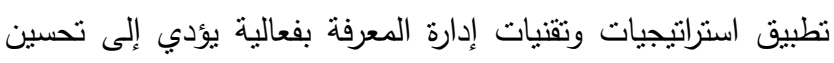

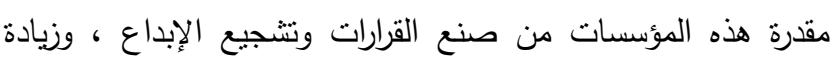

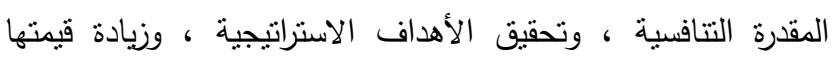

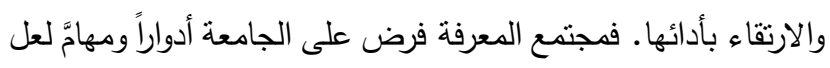

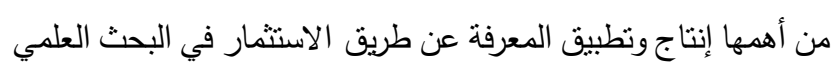

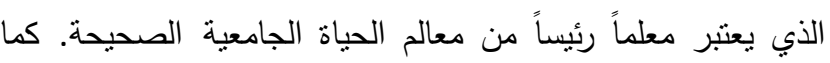
أثارت دراسة بريوير وبريوير(Brewer \& Brewer) إلى مئل أنّا المطلوب هو استخدام كافة الطرق للحصول على المعرفة الصريحة

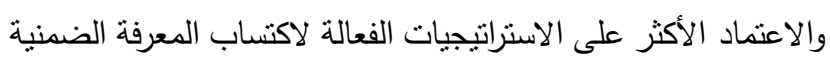

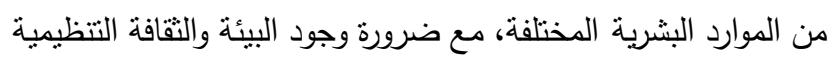
الداعمة التي لا ينبخي تجاهلها (30). 1- ومن هنا جاءت هذه الدراسة للكثف عن درجة ممارسة القادة الأكاديميين

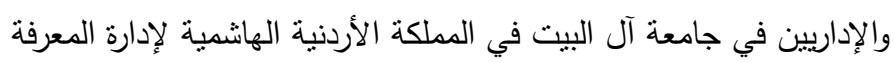
من وجهة نظر العاملين فيها. 
4. يمكن للمؤسسة الاستفادة من المعرفة ذاتها كسلعة

نهائية عن طريق بيعها والمتاجرة بها واستخدامها لتعديل منتج معين أو لإيجاد منتجات جديدة.

5. توجه المعرفة الإدارية مديري المؤسسات إلى كيفية

إدارة منظماتهم.

6. أصبحت المعرفة الأصل لتحقيق الميزة التتافسية وإدامنها.

مما سبق يمكن القول بأنّ نجاح المؤسسات في هذا العصر يقوم على المعرفة، تنشأ في إطارها وتنزود من مناهلها، وتنمو باستخدامها، وتتطور بالجديد منها، وقد تتتهي حين لا تتمكن من الحصول على الموارد المعرفية اللازمة لاستمرارها، ومن المُحنمّ أنّ كفاءتها وقدراتها النتافسية قد تتخفض حين تتقادم Lee \& أرصدتها المعرفية. وأكدت دراسة كل من لي ونتوي( (Choi, مجموعة من المبادئ تتضمنها إدارة المعرفة وأهمها: التعاون: وهو المستوى الذي يستطيع فيه العاملون في المؤسسة من العمل كفريق واحد مما يسهل عملية النشارك المعرفي. الثقة: مما يسهل عملية التبادل الحقيقي والمؤثر للمعرفة. التعلم: وهو عملية اكتساب المعرفة الجديدة، ومن قبل العاملين القادرين والمستعدين لاستخدام تلك المعرفة في نطوبر المنتجات والخدمات وحل المشكلات إن وجدت. اللامركزية: وهي تشير إلى تفويض الصلاحيات، حيث إنّ توليد المعارف يحتاج إلى اللامركزية العالية.

تسريلات ودعم نظم تكنولو جيا المعلومات: التي تدعم عمليات إدارة المعرفة.

الخبرة الواسعة والعميقة للعاملين: ويعني ذلك أن تكون خبرة العاملين بالمؤسسة واسعة أفقيا ومنتوعة وتخصصيه. وتعد عناصر المعرفة البنية التحتية لإدارة المعرفة التي تحوي على مجموعة من العناصر التي على المؤسسات الاهتمام بها وهي: الثقافة التظظيمية: هي عبارة عن مجموعة من القيم والمعتقدات الموجودة داخل المؤسسة وبين العاملين مثل طريقة تعامل الأفراد مع بعضهم البعض، وتوقعات كل فرد من الآخر ومن المؤسسة. ويتطلب تطبيق إدارة المعرفة في أي مؤسسة أن تكون القيم الثقافية السائدة منوافقة مع التعليم المستمر وإدارة المعرفة، وأن تكون كذلك مشجعة لروح فريق العمل وتبادل الأفكار ومساعدة الآخرين.
وتحويل المعلومات والخبرات التي تمتلكها المنظمة وتوظيفها في أنشطتها الإدارية المختلفة كاتخاذ القرارات وإجراءات العمل

والتخطبط الاستراتيجي"(7).

وتُعرف إجرائيا: بالدرجة الكلية لاستجابات أفراد عينة الدراسة على الأداة التي استخدمها الباحث لقياس درجة ممارسة القادة الأكاديمبين والإداريين في جامعة آل البيت في المملكة الأردنية الهاشمية لإدارة المعرفة.

حدود الاراسة ومحدداتها: تتحدد الدراسة الحالية بالمحددات الآتية: حدود موضوعية: اقتصرت الدراسة على موضوع درجة ممارسة القادة الأكاديميين والإداريين في جامعة آل البيت في المملكة الأردنية الهاشمية لإدارة المعرفة.

حدود بشرية: اقتصرت الدراسة على عينة من العاملين في جامعة آل البيت. حدود مكانية: جامعة آل البيت/ الأردن.

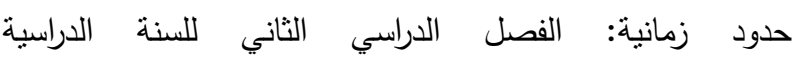
. 2019/2018) المحددات: إنّ تعميم نتائج الدّراسة الحالية تتحدد في ضوء صدق وثبات أداة الدِّراسة، ودقة وموضوعية استجابات أفراد عينة الدِّراسة على فقرات أداة الدِّراسة. الأدب النظري والدراسات السابقة: تناول هذا الجزء عرضاً للأدب النظري والدراسات السابقة ذات

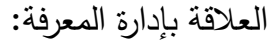

تبرز أهمية المعرفة للمؤسسات ليس في المعرفة ذاتها، وإنما فيما تضيفه إليها من قيمة، وما تؤديه لها من دور في تحولها إلى الاقتصاد الجديد المعتمد على المعرفة، الذي يتم التأكيد فيه على رأس المال الفكري القائم على الأفكار والخبرات والممارسات الأفضل، والكوادر البشرية المؤهلة والمدربة، وبالإمكان تحديد أهمية

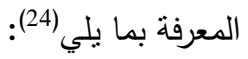

1. أسهوت المعرفة في مرونة المؤسسات من خلال دفعها لاعتماد أشكال التتسيق والتصميم والهيكلة فتكون أكثر

$$
\text { مرونة. }
$$

2. أتاحت المعرفة المجال للمؤسسة للتركيز على الأقسام الأكثر إبداعاً، وحفزت الإبداع والابتكار .

3. للمعرفة دور في تحول المؤسسات إلى مجتمعات معرفية

تحدث التعيير الجذري في المؤسسة، لتتكيف مع التغيير المتسارع في بيئة الأعمال، ولتواجه التعقيد

$$
\text { المتزايد فيها. }
$$


ومنها نموذج (Fraun Hofer)الككون من ست مراحل وهي كما يلي (28) ):

تتخيص المعرفة: وفي ضوئها ينم تحديد المعرفة المتاحة ومقارنتها بالمعرفة المطلوبة، وبذلك نحدد فجوة المعرفة .

مرحلة تحديد أهداف المعرفة: التي تحدد أساليب العمليات المعرفية الأخرى (كالتوليد، والخزن) ومن هذه الأهداف (تحسين العمليات، خلق الوضوح حول مجالات عمل المؤسسة) وبدون ذلك تصبح مجرد الاهن

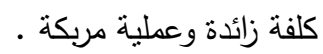
إنتاج وتوليد المعرفة: من خلال الثراء أو الاكتشاف أو الاكتساب، علماً أنه قد يتجسد التوليد بفكرة يقدمها الفرد .

تخزين المعرفة: للاحتفاظ بها وإدامتها والحصول عليها عند الحاجة . توزيع المعرفة: وذلك عن طريق الاستخدام والمشاركة وتبادل الأفكار

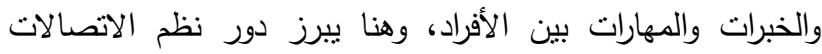

$$
\text { الرسمية وغير الرسمية في النشر والتوزيع • }
$$

تطبيق المعرفة: تنثير إلى الاستعمال وإعادة الاستعمال والاستفادة والاستثمار، وانّ تطبيق المعرفة هو غاية إدارة المعرفة وهي تعين على استثمار المعرفة المتاحة وان تطبئ.

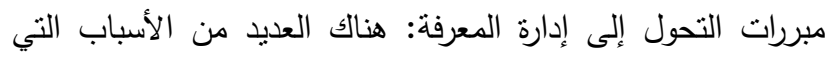

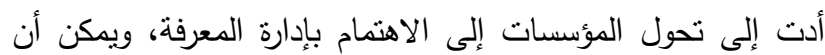
نلخص هذه المبررات بالآتي (14):

1. أهمية دور المعرفة في النجاح المؤسسي، لكونها فرصة لتخفيض التكلفة ورفع موجودات المؤسسة لتوليد إيرادات

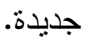

2. العولمة التي جعلت المجتمعات العالمية الآن على اتصال

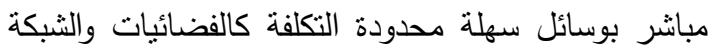

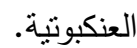
3. إمكانية قياس المعرفة ذاتها، وذلك عن طريق تلمس أثر

$$
\text { المعرفة على عمليات المؤسسة. }
$$

4. إدراك أسواق المال والأعمال العالمية أنّ المعرفة (التي تعتبر من أهم موجودات رأس المال الفكري في المؤسسات) هي مصدر الميزة التتافسية، بل وأهم من الدصادر التقليدية، مثل الأرض ورأس المال والعمل. 5. تشعب إدارة المعرفة وتزايد احتمالات نطبيقها، بل ووجود أنواع متعددة من المعرفة وأنواع متعددة من النظم والعمليات التي تدعم تطبيقها.
وهناك بعض العوامل التي تمكن العاملين من فهم نقافة المؤسسة

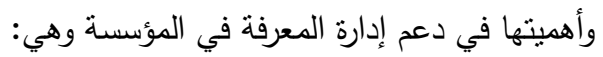

- مقدرة الإدارة على دعم عمليات تطبيق المعرفة في جميع

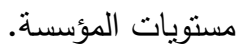
مقدرة الإدارة على تقديم الحوافز والعوائد للعاملين الذين يدعمون مشاركة المعرفة في المؤسسة. - مقدرة الإدارة على دعم وتشجيع التفاعل بين العاملين ودعم

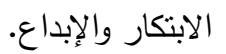

الهيكل التنظيمي: الهياكل التنظيمية توضح التسلسل الإداري للمؤسسة وكيفية تفاعل العاملين مع بعضهم البعض ومسئوليات

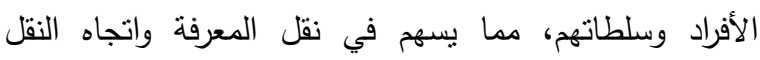
والمشاركة، فهي تسهل عمل إدارة المعرفة من خلال ما يلي :

$$
\text { • تقسيم العمل وتحديد أدوار الأفراد في المؤسسات . }
$$

• التحول من النظم المركزية التي تعتمد على احتكار المعرفة

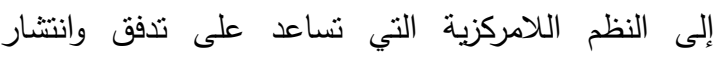

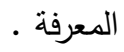

• التحول من أنماط التظيم القائمة على العمل الفردي إلى إعلى إعلى

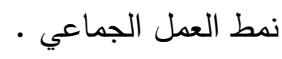

البيئة المادية: هي كل ما ينطلق بتصميم المباني والمكاتب وغرف الاجتماعات، فهناك كثيرٌ من الدراسات وجدت أنّ نسبة كبيرة من

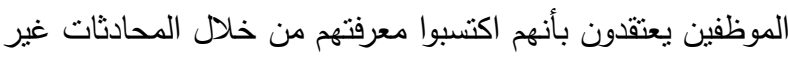

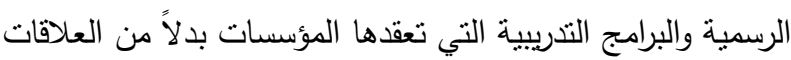
الرسمية .

البنية التحنية لتكنولوجيا المعلومات: تخدم البنية التحتية لتكنولوجيا المعلومات الكثير من العمليات مثل معالجة البيانات وتصنيفها

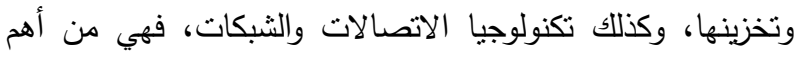

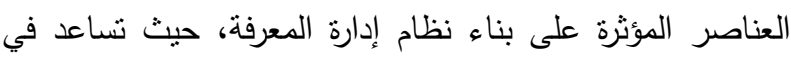

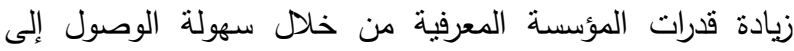
المعرفة وتجميعها ومن ثم تصنيفها وتخزينها، وبعد ذلك نشرها عبر

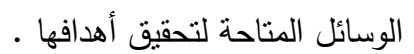
المعرفة المشتركة: نثير المعرفة المشتركة إلى التجارب والخبرات

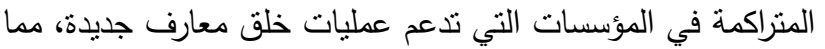
يزيد الابتكار والإبداع في المؤسسة. عمليات إدارة المعرفة: لا يوجد اتفاق بين العلماء والباحثين على عدد

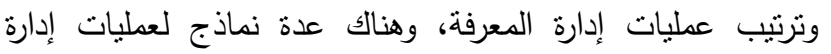
المعرفة التي قدمها المختصون والمهتمون في مجال إدارة المعرفة 
في المملكة العربية السعودية، وانتهاء بوضع تصور مقترح لإدارة المعرفة في الجامعات السعودية. استخدم الباحث المنهج الوصفي

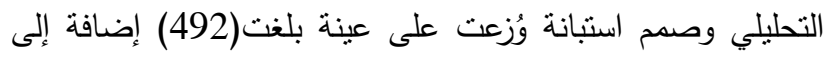

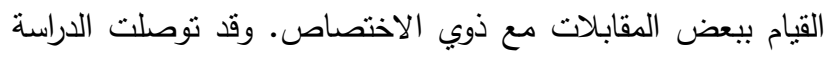

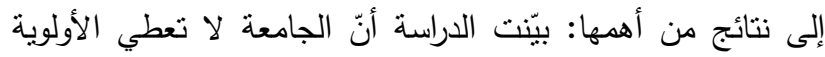

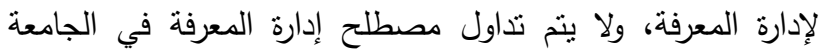
بشكل مكثف.لا توجد استراتيجية واضحة لإدارة المعرفة في الجامعة. وجود فروق ذات دلالة إحصائية بين متوسطات استجابات أفراد عينة

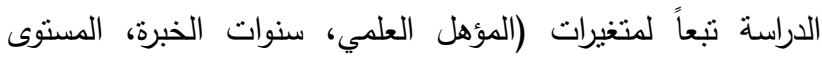

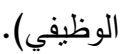

وأجرى رالف (Ralph) (35) دراسة هدفت إلى تحديد ما إذا كانت القاعدة المعرفية لتغطية الاستفسار تعتبر أداة فعالة لإدارة المعرفة من خلال بحث ما إذا كانت القاعدة المعرفية قيد الاستخدام، ومعرفة

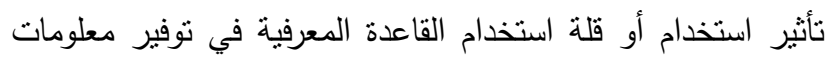

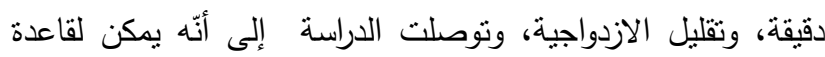

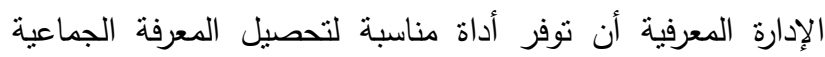
لمكتبيي المراجع في المكتبات الأكاديمية مع إمكانية توفيرها لاستخدامات مستقبلية، وأنّ قلة استخدام قواعد البيانات واستمرارية حالة عدم الدقة والازدواجية أدت إلى عدم فعالية القاعدة المعرفية

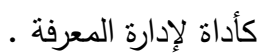

أجرى أبو النادي (1) دراسة هدفت إلى تقديم قواعد مقترحة لإدارة

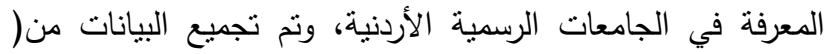

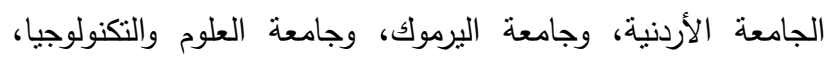

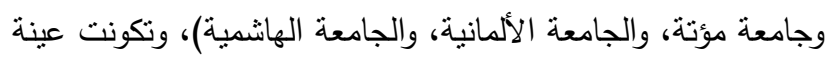

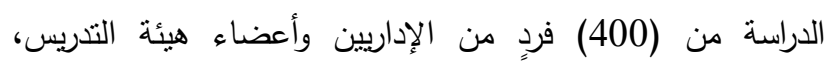

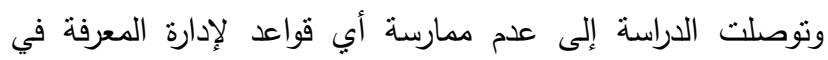

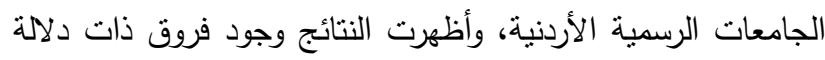

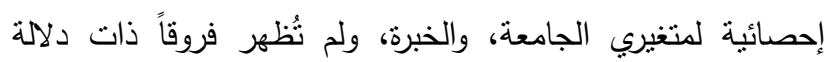

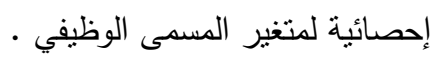

كما أجرى عودة (23) دراسة هدفت إلأى التعرف على واقع إدارة

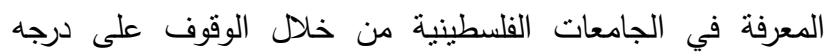

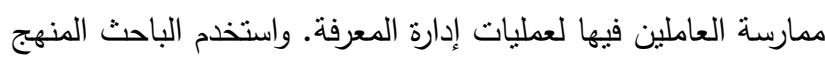
الوصفي التحليلي، وقام بتصميم استبانة تمثل عمليات إدارة المعرفة،

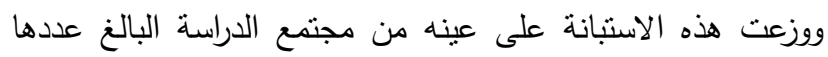
(347) موظفا من العاملين الإداريين في الجامعة الإسلامية وجامعة الإنة الأقصى وجامعة الأزهر ونم اختبارهم بالطريقة العشوائية وأسفرت نتائج الدراسة عن عدم وجود فروق ذات دلالة إحصائية لواقع إدارة

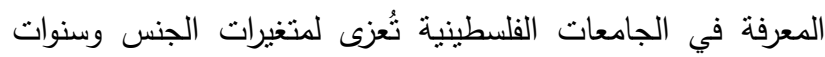
الخدمة، ونوصلت الدراسة إلى عدد من الأطروحات التي تتمنل في:
6. إدراك أنّ القيمة الحقيقية للمعرفة البعيدة المدى لا تعتمد

بالضرورة على قيمتها في لحظة توليدها.

7. الطبيعة الديناميكية للموجودات المعرفية وإمكانية تطويرها

بشكل مستمر، مما يجعل إدارتها عملية معقدة، ومن ثم لثردية التوجه نحو إيجاد برامج لإدارة المعرفة.

8. التغير الواسع والمنسارع في اتجاهات المستقيدين، مما جعل الأنماط الإدارية التقليدية غير ملائمة لمواكبة تلك التغيرات.

9. اتساع المجالات التي نجحت إدارة المعرفة في معالجتها، خصوصاً في مجالات التتافس والإبداع والتجديد.

ومن مسوغات تطبيق إدارة المعرفة في المؤسسات التعليمية: تعد

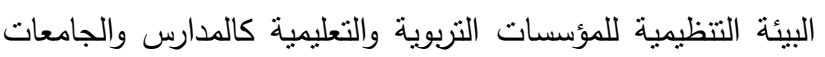
والكليات من أكثر البيئات المناسبة لتطبيق إدارة المعرفة، بل تكاد أن تكون أكثر البيئات احتياجاً فعلياً لنطبيق هذا الففهوم داخلها مقارنة

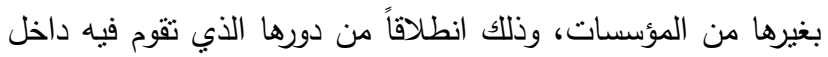
المجتمع، إذ تعتبر الجامعات والكليات بمختلف أنواعها هي المسؤولة

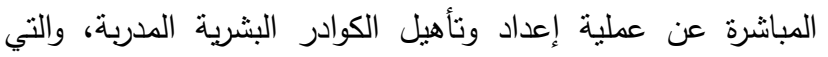
تعتبر العنصر الأساسي لأغلب عمليات التتمية المجتمعية، مما يلزم

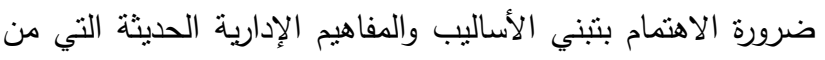

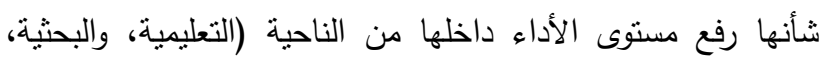

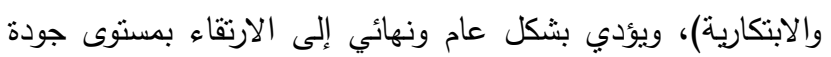
مخرجاتها (2).

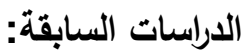
تم عرضها حسب التسلسل الزمني من الأقدم للأحدث:

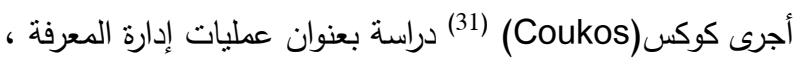
هدفت الدراسة إلى تقييم استخدام إدارة المعرفة في الجامعات،

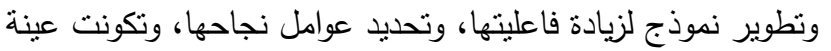

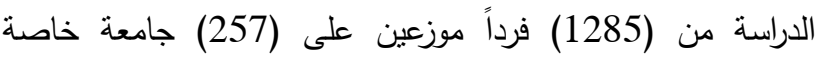

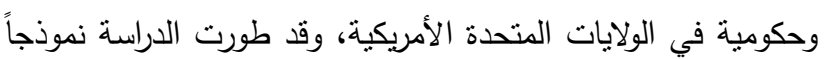

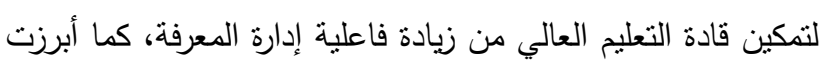

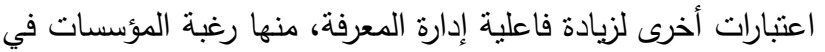
المبادرة بتطبيق ذلك النوع من الإدارة.

قام العتيبي (20) بدراسة هدفت إلى توضيح مفهوم إدارة المعرفة

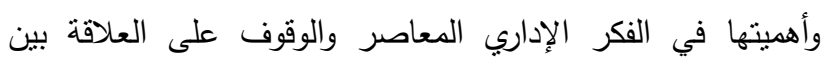
الجامعة وإدارة المعرفة انطلاقاً من رصيد الجامعة المعرفي والفكري الهدي ودورها في بناء العنصر البشري، وكذلك تحديد أهم عمليات إدارة

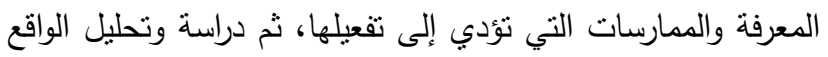

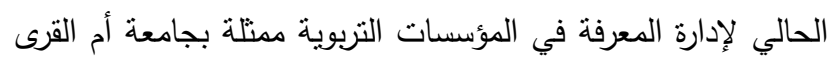


التخصصات العلمية، كما أظهرت نتائج الدراسة عدم وجود فروق جوهرية في الثقديرات في مجال تتمية مجتمع المعرفة وفي الدور

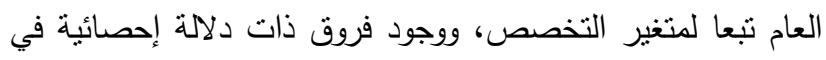

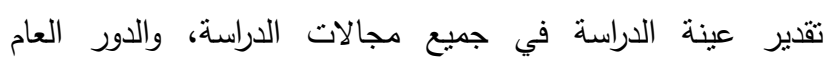

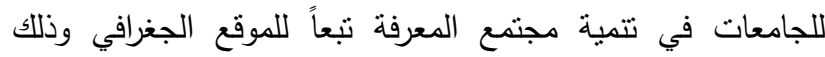
لصالح الجامعات في البلدان العربية . كما هدفت دراسة المنصوري(27) إلى معرفة درجة تطبيق عمليات

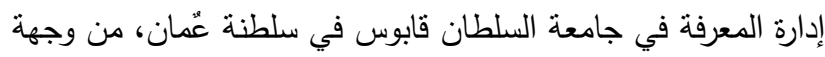
نظر أعضاء هيئة التدريس فيها. وتكونت عينة الدراسة من (207) أعضاء هيئة تدريس، ولتحقيق هدف الدراسة أعدت استبانة نكونت هن بصورتها النهائية من (36) فقرة موزعة في خمسة مجالات هي لهي

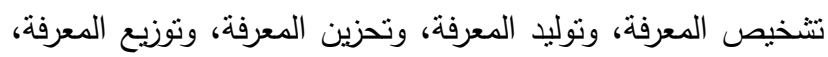
وتطبيق المعرفة، وأظهرت النتائج عدم وجود فروق ذات دلالة الدانة إحصائية تعُزى لأثر متغيرات الدراسة (الجنس، الرتبة الأكاديمية، الجنسية)، في حين وجدت فروق ذات دلالة إحصائية بين منوسط العابه استجابة أعضاء هيئة التدريس حول درجة نطبيق عمليات إدارة دار دارة

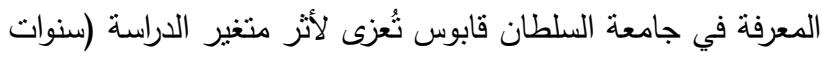

الخبرة، والكلية) ولصالح الكليات الإنسانية بالنسبة لمتغير الكلية. وأجرى كل من الأغا وأبو الخير (3) دراسة هدفت إلى الكثف عن واقع تطبيق عمليات إدارة المعرفة في جامعة القدس المفتوحة وإجراءات

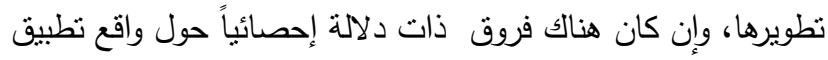
عمليات إدارة المعرفة بجامعة القدس المفتوحة تُعزى لـتغيرات (سنوات الخدمة، المنطقة التعليمية، المؤهل العلمي)، وتم استخدام

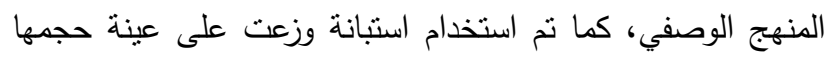

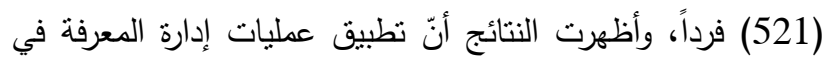

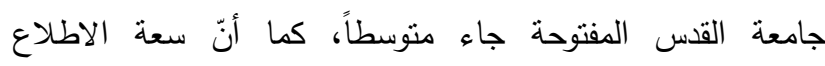

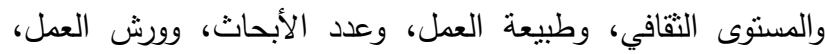

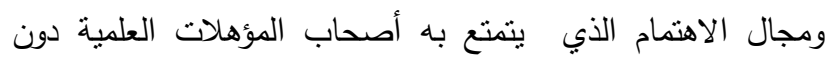

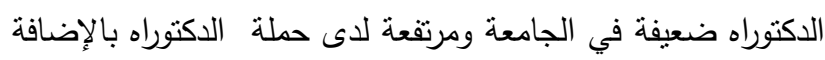
إلى أنّه لا نتوجد فروق دالة إحصائياً حول واقع نطبيق إدارة المعرفة لإنة

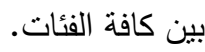

وأجرى كل من الطحاينة والخالدي(18) دراسة هدفت إلى تعرّف درجة

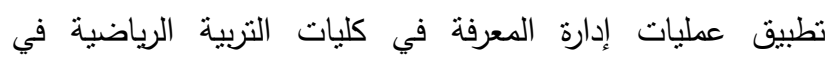
الجامعات الأردنية من وجهة نظر أعضاء هيئة التدريس، وطبقت

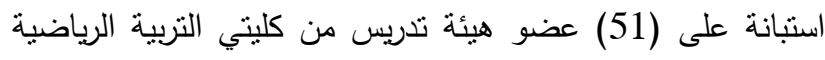

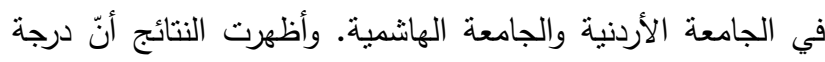

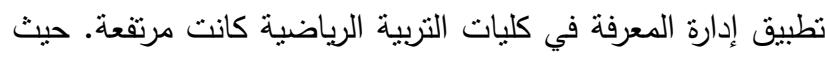

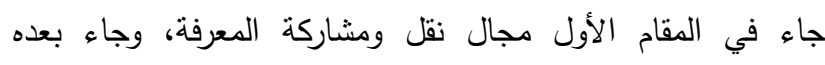
عمليات تخزين وتتظيم المعرفة، وكان أخر ما جاء مجال نال تكوين
وضع روية استراتيجية للتعليم العالي، والعمل على إيجاد برامج محفزة للبحث العلمي، وتحويل الجامعات إلى حاضنات لمشروع صناعة

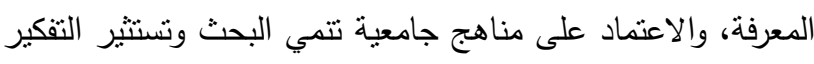

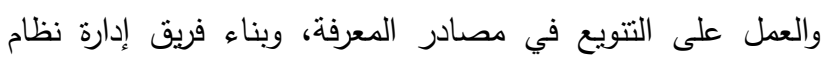
المعرفة لمتابعة نظم إدارة المعرفة في الجامعات الفلسطينية. أجرى ماضي (25) دراسة هدفت إلى بيان دور إدارة المعرفة في

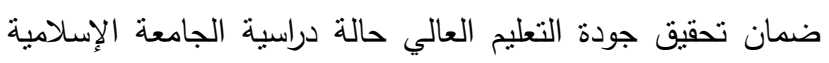

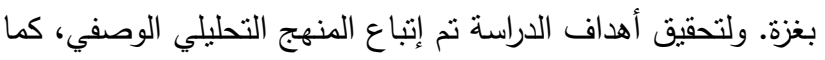

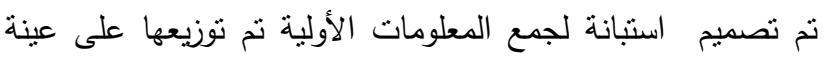

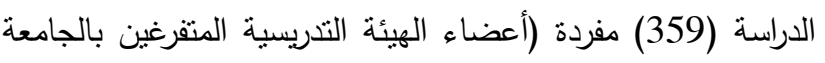
الإسلامية بغزة)، وتوصلت الدراسة إلى عدد من النتائج كان أهمها :

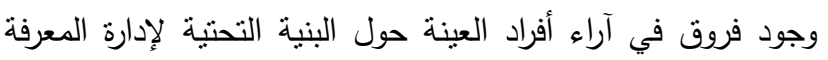

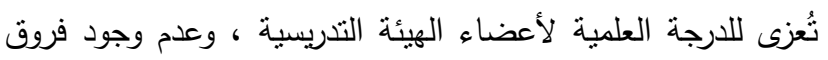
في آراء أفراد العينة حول ضمان الجودة تُعزى للارجة العلمية لأفراد

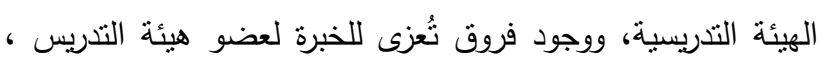
ووجود علاقة بين حوسبة المكتبات وضمان تحقيق جودة التعليم العالي. عدم وجود علاقة بين إيصال الانترنت مع مكاتب الهيئة

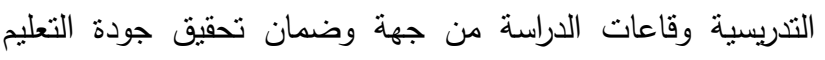
العالي من جهة أخرى، وكذلك وجود علاقة بين توفير المستلزمات

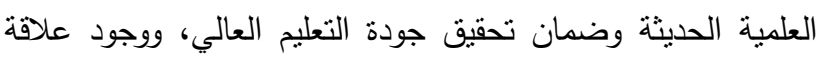

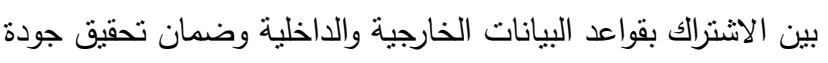
التعليم العالي، كذلك وجود علاقة بين تتويع المكتبة وضمان تحقيق

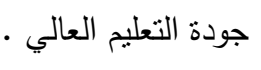

كما قام الزطمه(12) بدراسة هدف من خلالها إلى بيان دور

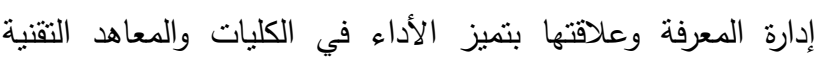
المنوسطة العاملة في قطاع غزة. واشتملت عينة الدراسة على (279)

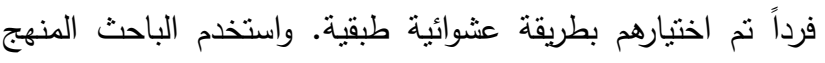

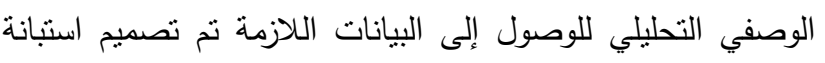

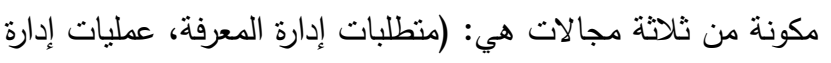

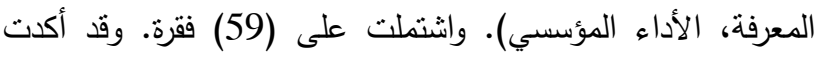

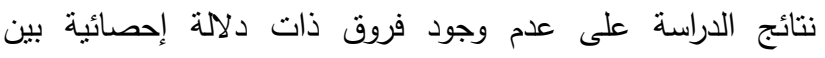

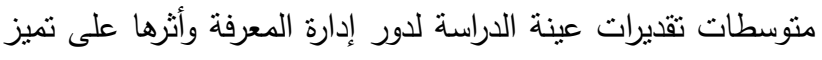
الأداء تُعزى لمتغير مدة الخدمة لصالح سنوات الخبرة الأكبر . كما أجرى بركات وعوض(4) دراسة هدفت التعرف إلى دور

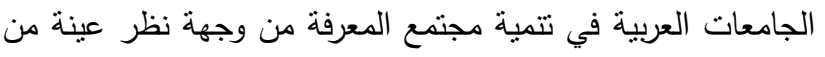
أعضاء هيئه التدريس فيها. وتكونت العينة من (123) عضو هيئة فئنة تدريس يعملون في بعض الجامعات العربية ، وأظهرت النتائج وجود

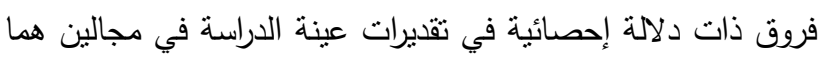

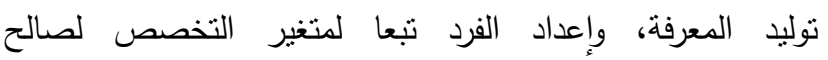


الجماعي، ثم جاء مجال تكوين رؤية جماعية مشتركة ، وجاء في المرتبة الأخيرة القيادة الاستراتيجية الداعمة للتعلم.

وأجرت خريسات(9) دراسة هدفت الوقوف على المقومات الأساسية

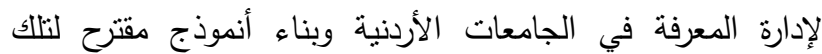
الكقومات، وقد استخذمت الباحثة أسلوب دلفاي التتبؤي الذب يقوم على استطلاع آراء الخبراء والمتخصصين في تلك المقومات؛ إذ إذإي اختارت عينة قصدية مؤلفة من (30) خبيراً في الإدارة التربوية، وإدارة مؤسسات التعليم العالي، وذوي الاهتمام بالفكر التربوي، وقد استجاب من هؤلاء الخبراء (25) خبيراً. وقد أفرزت نتائج الدراسة الاسة (28) فقرة خاصة بأهية إدارة المعرفة، و (30) فقرة خاصة

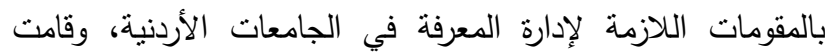

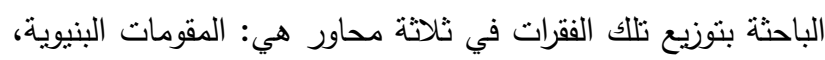
والمقومات الإجرائية، والمقومات الداعمة. وأظهرت النتائج أهمية

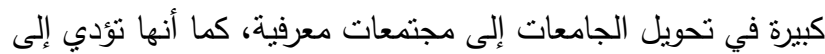
ظهور المبادرات الإبداعية، وتحقيق الميزة التتافسية التي تسعى إليها المؤسسات الإنتاجية والخدمية في القرن الحادي والعشرين، كما

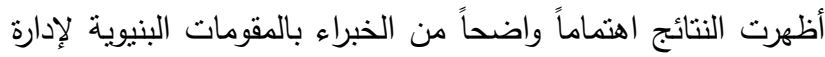
المعرفة متمنلة بالروئة الواضحة لدى العاملين في الجامعات من

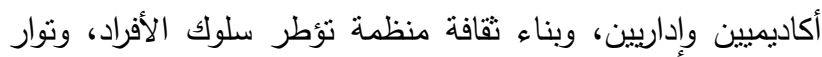

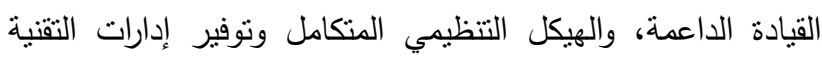

المتقدمة.

وأجرى الثراري(15) دراسةً هدفت إلى الكثف عن مدى ممارسة معلمي العلوم لعمليات إدارة المعرفة من وجهة نظرهم في إدارة تعليم

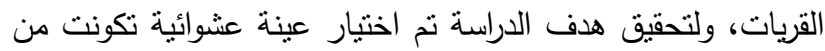
(203)معلم ومعلمة، ولتحقيق هدف الدراسة طبق أداة لقياس مدى لئس ممارسة عمليات إدارة المعرفة، أظهرت نتائج الدراسة أنّ درجة ممارسة عمليات إدارة المعرفة لدى معلمي العلوم كانت ممارستها بدرجة مرتفعة، وعدم وجود فروق ذات دالة إحصائية تُعزى لكتغير

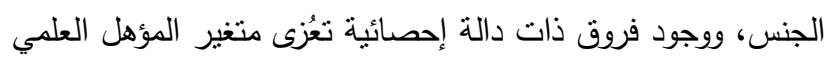

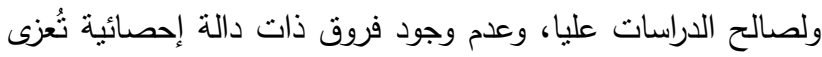
لمتغير الخبرة.

أجرى العدوان وطناش(21) دراسة هدفت إلى تعرف واقع دور إدارة

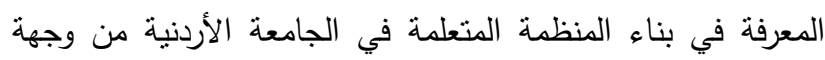
نظر القادة الأكاديميين وأعضاء هيئة التدريس، وأُستخدم في الدراسة الأنية هن وجنة المنهج الوصفي المسحي، وتم اختيار عينة الدراسة بالطريقة الطبقية العشوائية بلغت (333) فرداً، وأظهرت النتائج: أنّ واقع دور إدارة المعرفة في بناء المنظمة المتعلمة من وجهة نظر القادة الأكاديميين وأعضاء هيئة التدريس في الجامعة الأردنية كان مرتفعاً ، وعدم وجود فروق ذات دالة إحصائية لدور إدارة المعرفة في بناء المنظمة الإنهاء
وتوليد المعرفة، كما أظهرت النتائج عدم وجود فروق دالة إحصائياً في درجة تطبيق عمليات إدارة المعرفة تُعزى لمتغيرات الجنس والخبرة

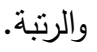
وأجرى كل من الزبون والثيخ(11) دراسة هدفت إلى معرفة واقع إدارة المعرفة في الجامعات الأردنية من وجهة نظر أعضاء الهيئة التدريسية وعلاقة ذلك ببعض المتغيرات. نكونت عينة الدراسة من (965) عضو هيئة تدريس اختيروا بطريقة عشوائية من عدة

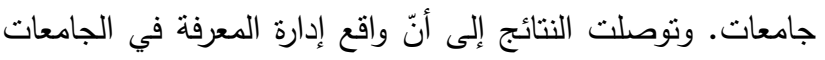
الأردنية الخاصة من وجهة نظر أعضاء هيئة التدريس والإداريين

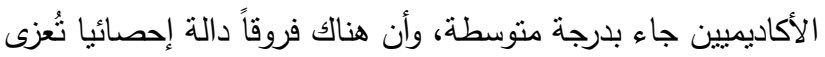
لمتغير الجنس، ولصالح الإناث، ولصالح مستوى الخبرة، ولمتغير

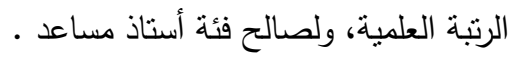

وأجرى التلباني وبدير والرقب(6) دراسة هدفت إلى التعرف إلى متطلبات نطبيق إدارة المعرفة في الجامعات الفلسطينية في قطاع

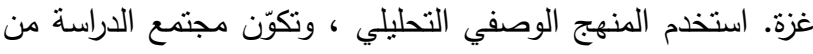

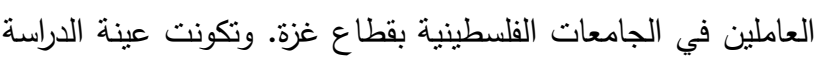
من (241) فرداً. وتوصلت الدراسة إلى وجود علاقة إيجابية بين منطلبات إدارة المعرفة (النقافة التنظيمية، الهيكل التتظيمي، القيادة،

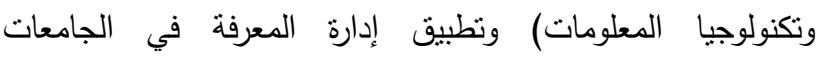
الفلسطينية .

كما أجرى خرابشة(8) دراسة هدفت إلى معرفة درجة نطبيق إدارة المعرفة في جامعة البلقاء النطبيقية من وجهة نظر أعضاء هيئة التدريس فيها. وتكون مجتمع الدراسة من أعضاء هيئة التدريس في

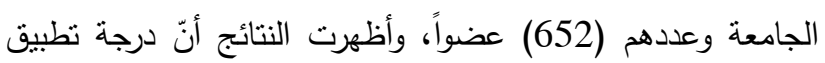
إدارة المعرفة في جامعة البلقاء التطبيقية كانت متوسطة، كما نوصلت التهات الدراسة إلى وجود فروق دالة إحصائياً تبعا لمتغيري الجنس ولصالح الذكور والمؤهل العلمي ولصالح الدكتوراه في متغير الرتبة العلية ولصالح الأستاذ المشارك وعدم وجود فروق في متغير الخبرة التدريسية في جميع المجالات . كما وأجرت صالح(16) دراسة هدفت إلى التعرف على درجة توظيف إدارة المعرفة لدى القادة الأكاديميين في الجامعات الأردنية

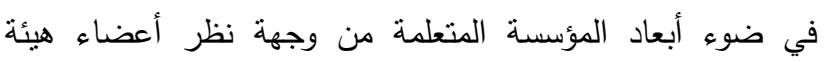

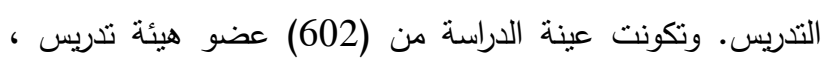

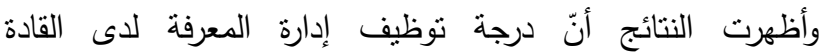
الأكاديميين في الجامعات الحكومية الأردنية كانت متوسطة ، وجاء

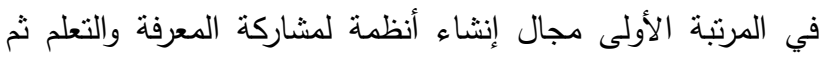

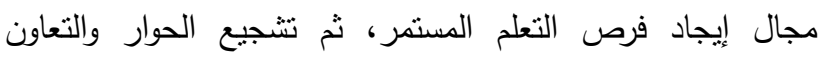




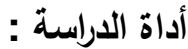

تم تطوير أداة لقياس متغيرات الدراسة فقد تكونت الأداة من(37) فقرة

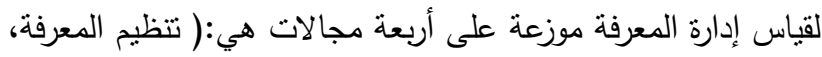

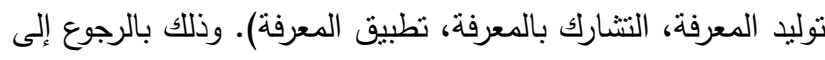
الأدب النظري والدراسات السابقة ذات العلاقة.

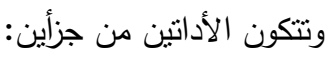
الجزء الأول: اشتمل على المعلومات الديمغرفية اللازمة عن

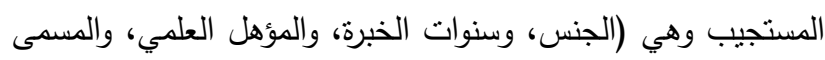

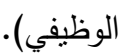
الجزء الثاني: استبانة لقياس إدارة المعرفة. وقد نم تحديد الإجابات بخمسة معايير هي (بدرجة كبيرة جداً، وبدرجة كبيرة، وبدرجة منوسطة، وبدرجة قليلة، وبدرجة قلبلة جداً ).

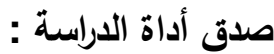

تم التحقق من صدق أداة الدراسة بطريقة صدق الدحتوى، وذلك

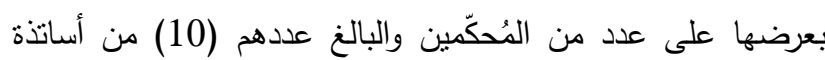
الإدارة التربوية والقياس والتقويم والإدارة العامة، من أساتذة الجامعات

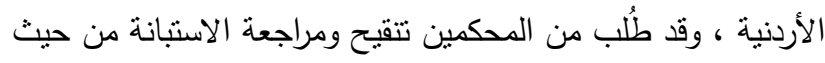
درجة وضوح الفقرات، وجودة الصياغة اللغوية، ودرجة انتمائها

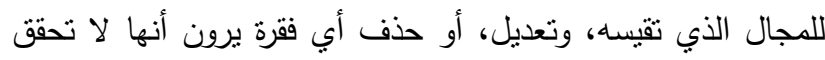

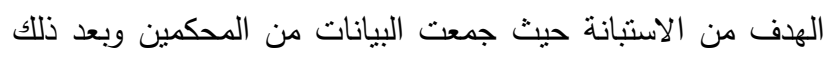
ثم إعادة صياغنها وفق ما وافق عليه (80\%) من المحكمين.

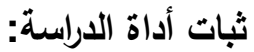

للتأكد من ثبات أداة الدراسة، نم استخدام طريقة الاتساق الداخلي

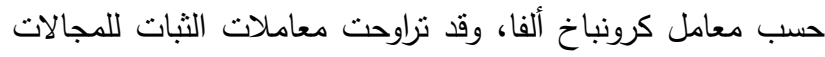
ما بين( - 0.910 .94 0.94)، وهذه القيم تُعدّ مقبولة لغايات هذاخدات

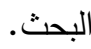

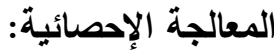

تم استخدام البرنامج الإحصائي (SPSS) لتفريغ البيانات للإجابة عن أسئلة الدراسة على النحو الآتي:

للإجابة عن السؤال الأول: تم استخدام المنوسطات الحسابية والانحرافات المعيارية.

للإجابة عن السؤال الثاني: تم استخدام المتوسطات الحسابية

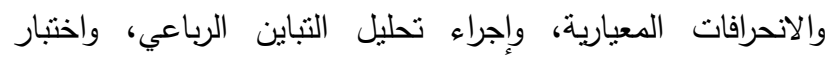
لمعرفة دلالة الفروق بين مستويات متغير سنوات الخبرة.
المتعلمة في الجامعة الأردنية من وجهة نظر القادة الأكاديميين وأعضاء هيئة التدريس، تبعا لمتغيرات الجنس، وطبيعة العطل، والجامعة التي تخرج فيها، والرنبة الأكاديمية. دراسة صلاح الدين والفارسية(17) هدفت الدراسة إلى تعرف درجة توافر منطلبات تطبيق إدارة المعرفة وأهيتها في الإثراف التربوي من وجهة نظر المشرفين بسلطنة عُمان في ضوء بعض المتغيرات،

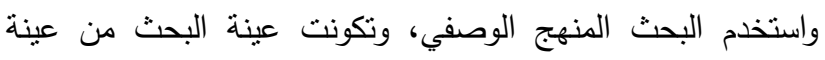

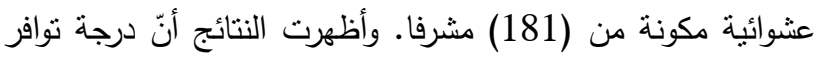

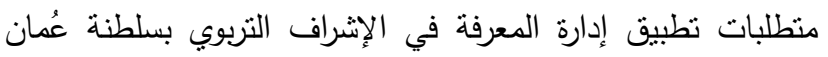

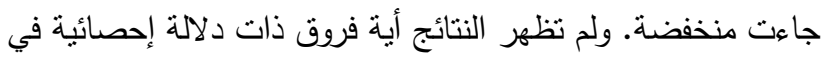
تقديرات أفراد العينة الكلية لدرجة توافر متطلبات تطبيق إدارة المعرفة تعزَى لمتغير الجنس، أو جهة العمل، أو الوظيفة . من خلال عرض الدراسات السابقة التي تتاولت بيئات مختلفة

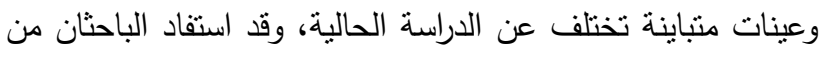

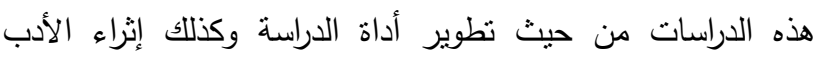

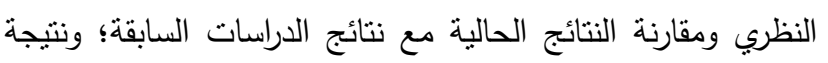
لما سبق ذكره من أدب نظري ودراسات سابقة جاءت هذه الدراسة

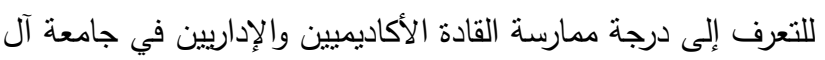

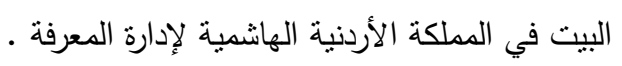

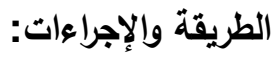

تتاول هذا الجزء وصفًا لمنهج الدراسة، ومجتمع الدراسة

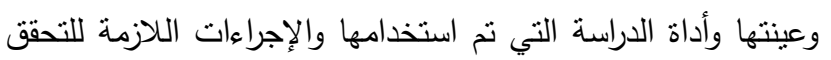
من صدق وثبات أداة الدراسة

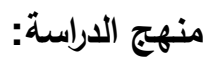
اتبعت الدراسة المنهج الوصفي المسحي لملاعمته لطبيعة الدراسة، وذلك باستخدام أداة لجمع البيانات من أفراد عينة الدراسة.

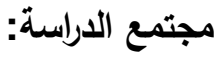

تكون مجتمع الدراسة من جميع العاملين في جامعة آل البيت في المملكة الأردنية الهاشمية والبالغ عددهم (1360) عاملاً موزعين على(435) عضو هيئة تدريس و (925) إدارياً (حسب إحصائيات دائرة ضمان الجودة، جامعة آل البيت

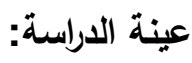
تم اختيار عينة طبقية عشوائية مكونة من (375) أكاديمياً وإدارياً

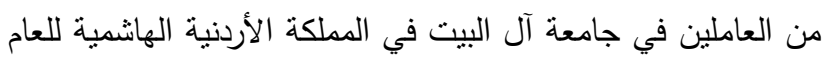
الدراسي 2019/2018، وبنسبة (24\%) من مجتمع الدراسة. 
ممارسة مجالات إدارة المعرفة، نراوحت ما بين (3.60-3.36)، حيث جاء مجال تنظيم المعرفة في الرتبة الأولى بأعلى متوسط حسابي بلغ (3.60)، وبانحراف معياري مقداره(0.80) وبدرجة منتسطة، تلاه في الرنبة الثانية مجال تولبد المعرفة بمتوسط حسابي بلغ (3.55)، وبانحراف معياري مقداره (0.81) وبدرجة منوسطة، تلاه في الرتبة الثالثة مجال تطبيق المعرفة بمتوسط حسابي بلغ (3.44) وبانحراف معياري مقداره(0.83) وبدرجة منوسطة، بينما جاء مجال التشارك في المعرفة في الرنبة الأخيرة وبمتوسط حسابي بلغ (3.36) وبانحراف

$$
\text { معياري مقداره(1.06) وبدرجة متوسطة. }
$$
وقد يُّعزى ذلك إلى أنّ هناك ممارسات متواضعة من قبل القادة في تطبيق مجالات إدارة المعرفة في إداراتهم للوحدات التنظيمية التي يقودونها، كذللك كان من أكثر اهتماماتهم تتظيم المعرفة وهذا ربما يعود السبب فيه إلى مطالب الرقابة المستمرة على الجامعة، بينما جاءت المشاركة في المعرفة أقل الممارسات وتفسر هذه النتيجة بأنّ هناك مركزية في المعلومات والممارسات الإدارية ، وتتمثل في تتفيذ الأوامر والتعليمات الصادرة رئاسة الجامعة. وقد اتفقت نتيجة هذه وردات الدراسة مع نتيجة دراسة كل من العتيبي(2007)؛ وعودة(2010)؛ والزطمة(2011)؛ والزبون والثيخ(2015)؛ خرابشة(2016)؛ صالح(2017)؛ وخريسات(2018)؛ وصلاح والفارسية(2021) والتي توصلت نتائجها إلى أنّ تطبيق إدارة المعرفة كان متوسطاً، بينما اختلفت هذه النتيجة مع نتيجة دراسات رالف Ralph, 2008$)$ والمنصوري(2011)؛ والشراري(2020)؛ والعدوان وطناش(2020) والتي توصلت نتائجها إلى أنّ نطبيق إدارة المعرفة جاء مرتفعاً. وتم حساب المتوسطات الحسابية والاتحرافات المعيارية لتقديرات أفراد عينة الدراسة على فقرات كل مجال منفرداً، حيث كانت على النحو التالي:

\section{المجال الأول: تنظيم المعرفة}

للإجابة عن فقرات هذا المجال تم استخراج المتوسطات الحسابية والانحرافات المعيارية والرتبة لفقرات مجال تتظيم المعرفة، والجدول(2) يوضح ذللك.
واعتمد الباحثان المتوسطات الحسابية لإجابات أفراد العينة لتكون مؤشراً على درجة التقدير وذلك اعتماداً على المعادلة الآتية: الحد الأعلى - الحد الأدنى / عدد المستويات = 5-1 / $1.33=33$

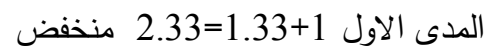
المدى الثاني 2.34+1.33=1.67 متوسط

$$
\text { المدى الثالث 3.68+1.33=5 مرتفع }
$$

نتائج الاراسة ومناقشتها تتاول هذا الجزء عرضاً لنتائج الدراسة وفقاً لتسلسل أسئلتها، وذلك على النحو الآتي:

النتائج المتعلقة بالسؤال الأول: ما درجة تطبيق القادة الأكاديميين والإداريين في جامعة آل البيث لإدارة المعرفة من وجهة نظر العاملين فيها؟. للإجابة عن هذا السؤال تم استخراج المتوسطات الحسابية والانحرافات المعيارية، والجدول(1) يبين ذلك: الجدول (1): المتوسطات الحسابية والانحرافات المعيارية والرتبة والدرجة

\begin{tabular}{|c|c|c|c|c|c|}
\hline الارجة & الرتبة & الانحراف & الحستوسطي & المجالات & الرقم \\
\hline متوسطة & 1 & 0.80 & 3.60 & تنظيم & 1 \\
\hline منوسطة & 2 & 0.81 & 3.55 & توليد & 2 \\
\hline متوسطة & 3 & 0.83 & 3.44 & تطبيق & 4 \\
\hline متوسطة & 4 & 1.06 & 3.36 & في النشارك & 3 \\
\hline متوسطة & - & 0.83 & 3.55 & الكلي & - \\
\hline
\end{tabular}

لمجالات إدارة المعرفة مرتبة تتازلياً

يبين الجدول (2) أنّ درجة نطبيق القادة الأكاديميين والإداريين في

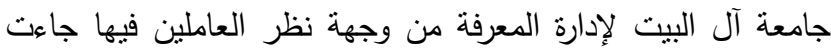
منوسطة، وبلغ المتوسط الحسابي ككل (3.55) وبانحراف معياري مقداره(0.83) وبدرجة متوسطة ، وأن المتوسطات الحسابية لدرجة

\begin{tabular}{|c|c|c|c|c|c|}
\hline 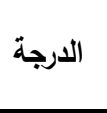 & الانحراف & الحستوسط & الفقرات & 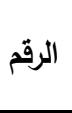 & الرتبة \\
\hline \multicolumn{6}{|c|}{ يقوم القادة الأكاديميون والإداريون بـ } \\
\hline 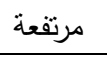 & 0.75 & 3.99 & جمع البيانات والمعلومات التي لها علاقة بمجال عملي. & 1 & 1 \\
\hline مرتفعة & 0.82 & 3.86 & استخدام الحاسوب في نتظيم وتخزين البيانات والمعلومات & 7 & 2 \\
\hline 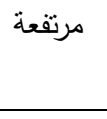 & 0.89 & 3.77 & جدولة البيانات والمعلومات المتوفرة لسهولة الوصول إليها عند & 4 & 3 \\
\hline منوسطة & 1.04 & 3.67 & تصنيف البيانات والمعلومات حسب أهميتها للاستفادة منها في & 2 & 4 \\
\hline
\end{tabular}
الجدول (2): المتوسطات الحسابية والانحرافات المعيارية والرنبة والدرجة لفقرات مجال تنظيم المعرفة مرتبة تتازلياً 


\begin{tabular}{|c|c|c|c|c|c|}
\hline 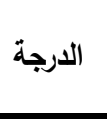 & الانحراف & المتوسط & 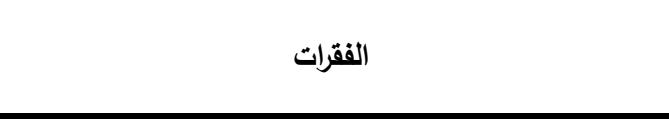 & الرقم & الرتبة \\
\hline \multicolumn{6}{|c|}{ يقوم القادة الأكاديميون والإداريون بـ } \\
\hline & & & 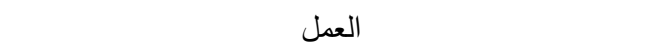 & & \\
\hline 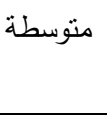 & 0.52 & 3.62 & تتجع تطوير المهارات الأدائية التي تسهل في عملية تتظيم & 6 & 5 \\
\hline متوسطة & 1.17 & 3.53 & ترتيب المعلومات المتوفرة حسب درجة أولويتها بالنسبة للعمل & 3 & 6 \\
\hline 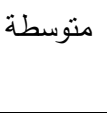 & 1.04 & 2.75 & تتظيم المعرفة على شكل صور وأثكال في منظومات بسيطة & 5 & 7 \\
\hline 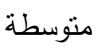 & 0.80 & 3.60 & الارجة الكلية للمجال & & \\
\hline
\end{tabular}

يبين الجدول (2) أنّ المتوسط الحسابي الكلي لمجال نتظيم المعرفة الأخيرة وبمتوسط حسابي بلغ (2.75) وبانحراف معياري مقداره(1.04) بلغ(3.60) وبانحراف معياري بلغ(20.80) وبدرجة منوسطة، أما وبدرجة منوسطة. المتوسطات الحسابية لفقرات هذا المجال فقد تراوحت مابين (3.99- المجال الثاني: توليد المعرفة

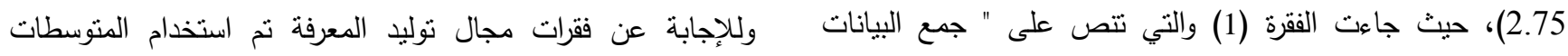

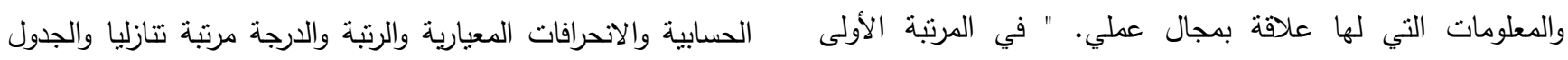

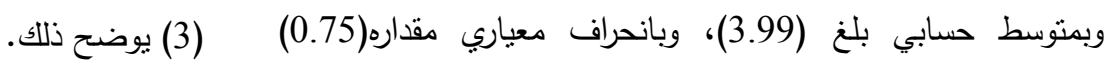

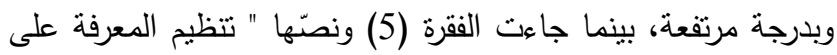
شكل صور وأنثال في منظومات بسيطة ذات معنى " بالمرتبة الجدول (3): المتوسطات الحسابية والانحرافات المعيارية والرتبة والدرجة لفقرات مجال توليد المعرفة مرتبة تنازلياً

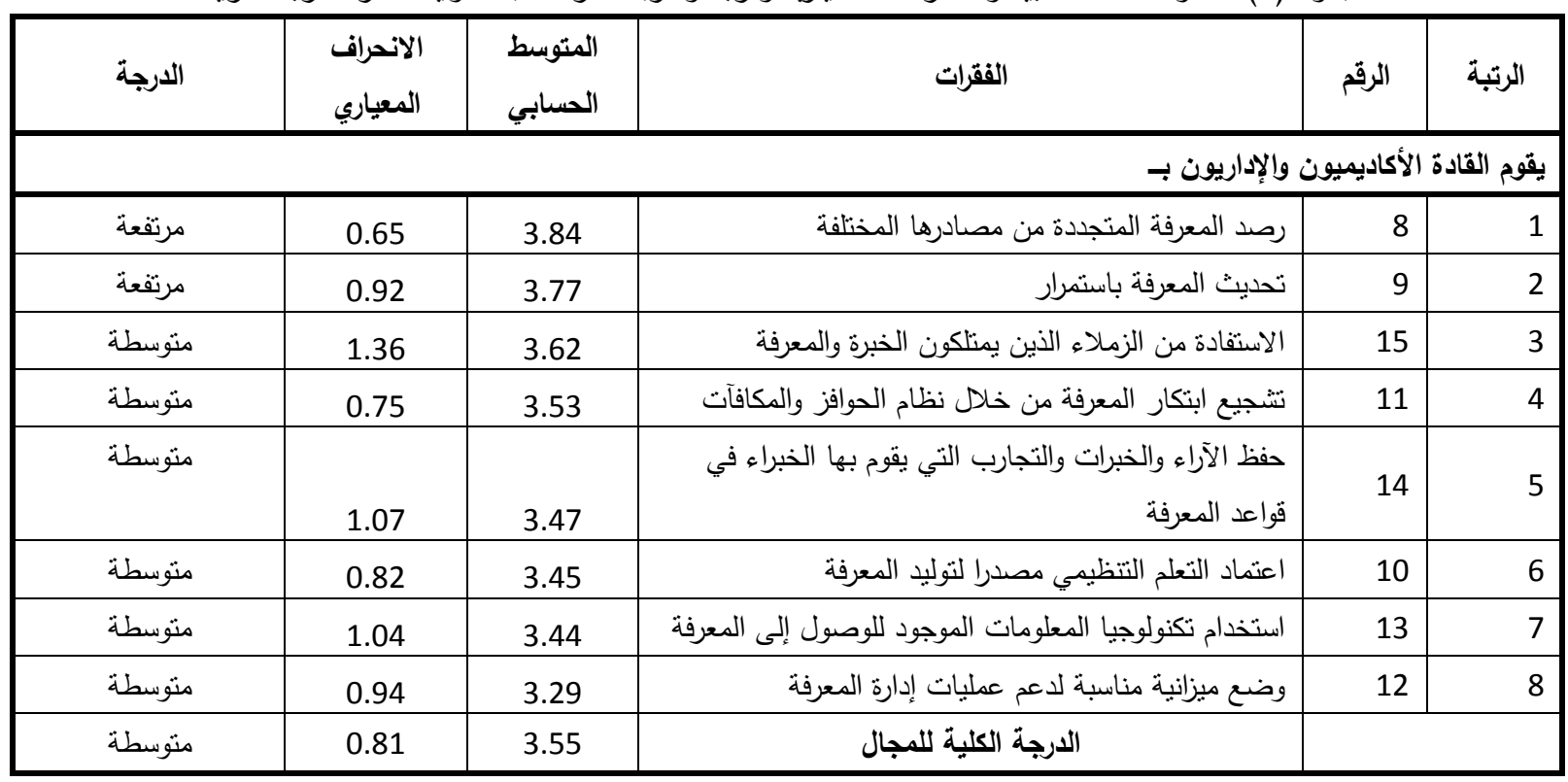

يبين الجدول (3) أنّ المنوسط الحسابي الكلي لمجال نوليد المعرفة المجال الثالث: التشارك في المعرفة

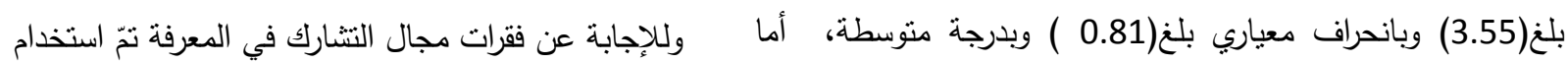
المتوسطات الحسابية والانحرافات المعيارية والرتبة والدرجة مرتبة المتوسطات الحسابية لفقرات هذا المجال فقد تراوحت ما بين (3.84تنازليا والجدول (4) يوضح ذلك.

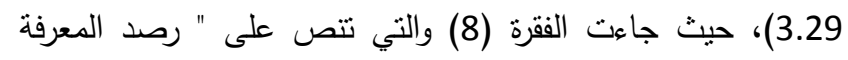

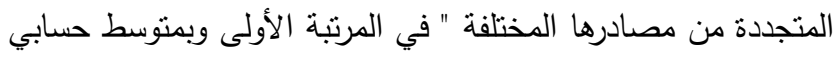

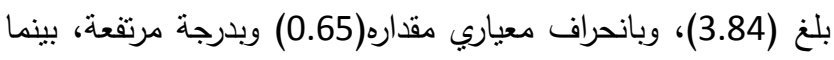
جاءت الفقرة (12) ونصها " وضع ميزانية مناسبة لدعم عمليات إدارة

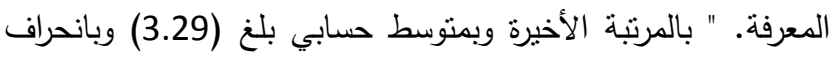
معياري مقداره(0.94) وبدرجة متوسطة. 
الجدول(4): المتوسطات الحسابية والانحرافات المعيارية والرتبة والدرجة لفقرات مجال التشارك في المعرفة مرنبة تتازلياً

\begin{tabular}{|c|c|c|c|c|c|}
\hline 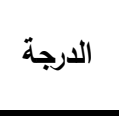 & الانحراف المعياري & الحسابي & 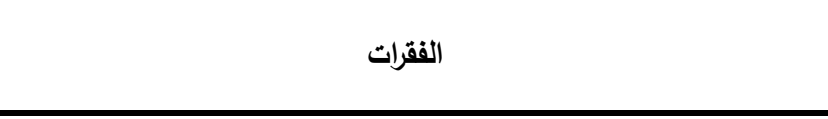 & 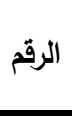 & الريبة \\
\hline \multicolumn{6}{|c|}{ يقوم القادة الأكاديميون والإداريون بـ } \\
\hline 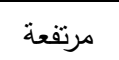 & 0.88 & 3.70 & الاستفادة من قاعدة البيانات المنوفرة لدى الجامعة للحصول على المعلومات & 25 & 1 \\
\hline 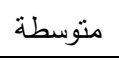 & 1.05 & 3.67 & النتواصل مع الزملاء لتبادل الآراء والأفكار & 19 & 2 \\
\hline 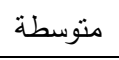 & 1.18 & 3.56 & اعتماد طريقة الوثائق والنشرات الداخلية لتوزيع المعرفة & 17 & 3 \\
\hline 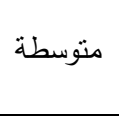 & 1.19 & 3.50 & بريد الكتروني،... الخدام تكنولوجيا خاصة للتشارك في المعرفة مثل (شبكة اتصال داخلي، & 18 & 4 \\
\hline 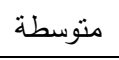 & 1.35 & 3.47 & المشاركة في ورش العمل للاستفادة من المعرفة الظاهرة والضمنية & 16 & 5 \\
\hline 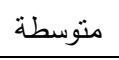 & 1.28 & 3.42 & تشجيع الدورات التدربيية والندوات لزيادة مهاراتي البحثية & 23 & 6 \\
\hline متوسطة & 1.15 & 3.29 & مشاركة وسائل الإعلام للاستفادة من عمليات إدارة المعرفة بشكل فعال & 24 & 7 \\
\hline منوسطة & 1.12 & 3.18 & تعزيز العلاقة بين ادارة الجامعة والمراكز البحتية & 26 & 8 \\
\hline متوسطة & 0.98 & 3.14 & نشر الأبحاث في المجلات المحلية والعالمية المحكمة لتوصيل المعرفة مع & 20 & 9 \\
\hline متوسطة & 1.24 & 3.13 & المشاركة في مؤتمرات علمية داخلية وخارجية من أجل نشر المعرفة & 21 & 10 \\
\hline منوسطة & 1.30 & 3.00 & استخدام البوابة الاكترونية لتبادل المعرفة مع الآخرين & 22 & 11 \\
\hline منوسطة & 1.06 & 3.36 & الارجة الكلية للمجال & & - \\
\hline
\end{tabular}

يبين الجدول ( 4) أنّ المتوسط الحسابي الكلي لمجال التتارك في " بالمرتبة الأخيرة وبمتوسط حسابي بلغ (3.00)، وبانحراف معياري المعرفة بلغ(3.36) وبانحراف معياري بلغ(1.06 ) وبدرجة متوسطة، مقداره (1.30) وبدرجة متوسطة.

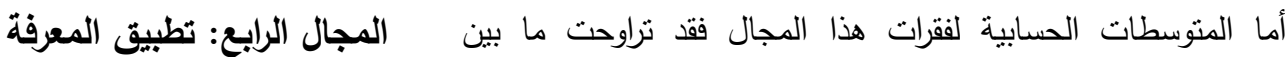
(3.70- 3.00)، حيث جاءت الفقرة (25) والتي تتص على " وللإجابة عن فقرات مجال نطبيق المعرفة تم استخدام المتوسطات

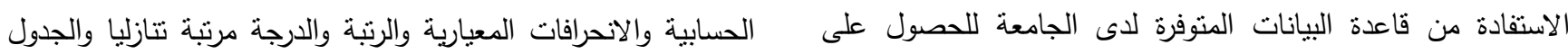

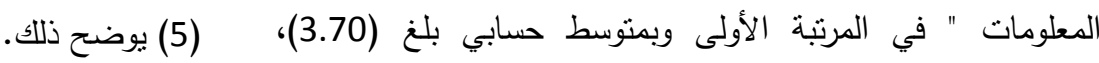
وبانحراف معياري مقدار(0.88) وبدرجة مرتفعة، بينما جاءت الفقرة

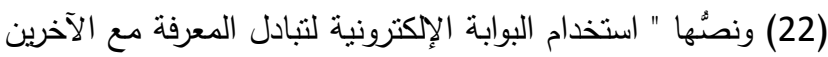

الجدول (5): المتوسطات الحسابية والانحرافات المعيارية والرتبة والدرجة لفقرات مجال تطبيق المعرفة مرتبة تنازلياً

\begin{tabular}{|c|c|c|c|c|c|}
\hline 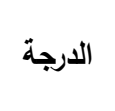 & المعياري & المسابي & 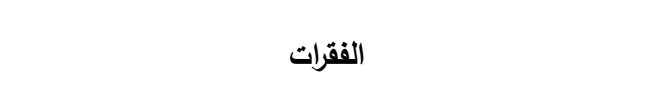 & 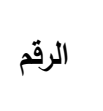 & 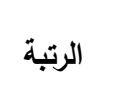 \\
\hline \multicolumn{6}{|c|}{ بقوم القادة الأكاديميون والإداريون بـ } \\
\hline 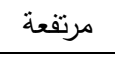 & 0.64 & 4.12 & الاستفادة من خبرات الآخرين البحثية في تطوير العمل & 37 & 1 \\
\hline 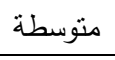 & 1.05 & 3.54 & توظيف المعرفة المكتسبة لتحقيق أهداف الجامعة & 32 & 2 \\
\hline 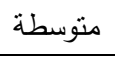 & 1.16 & 3.53 & الاهتمام بتطبيق المعرفة عند القيام بعملي & 30 & 3 \\
\hline 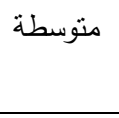 & 1.055 & 3.52 & باستمرار إستخدام المعرفة المتوفرة في تتمية المهارات الأدائية & 33 & 4 \\
\hline 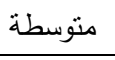 & 0.88 & 3.52 & التأكيد باستمرار على أهبة استخدام وتطبيق المعرفة & 28 & 5 \\
\hline 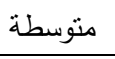 & 0.75 & 3.38 & امتلاك وسائل وأساليب تساعد على تطبيق المعرفة & 27 & 6 \\
\hline متوسطة & 0.87 & 3.30 & تتمية المدرات الإبداعية من خلال الاستخدام المنظم للمعرفة & 34 & 6 \\
\hline متوسطة & 0.69 & 3.29 & استخدام التقنيات التكنولوجية في عملية التعلم والتعليم & 36 & 8 \\
\hline 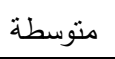 & 1.27 & 3.27 & تطبيق المعرفة المتوفرة في حل المشكلات. & 31 & 9 \\
\hline متوسطة & 1.12 & 3.17 & المشاركة في البرامج التدريبية على إدارة المعرفة & 29 & 10 \\
\hline
\end{tabular}




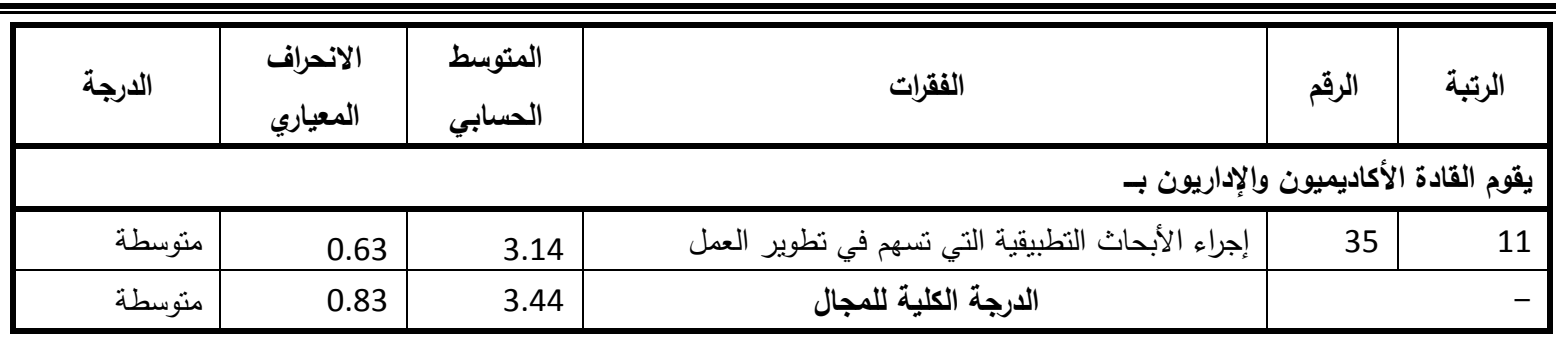

النتائج المتعلقة بالسؤال الثاني: هل هناك فروق ذات دلالة إحصائية

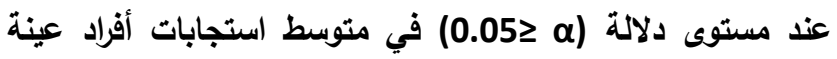

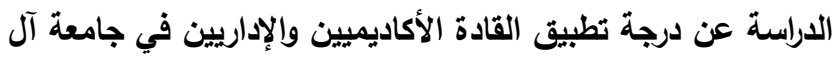

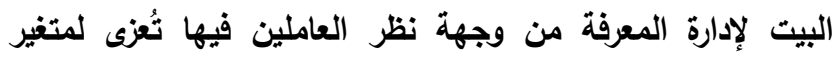

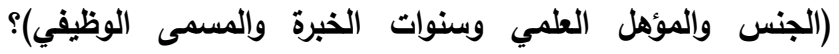

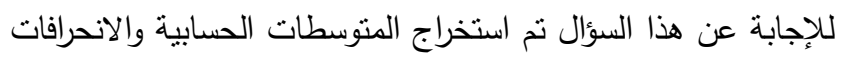
المعيارية، حسب متغيرات الجنس المؤهل العلمي وسنوات الخبرة والمسمى الوظيفي والجدول (6) يوضح ذلك.
يبين الجدول ( 5) أنّ المتوسط الحسابي الكلي لمجال تطبيق المعرفة

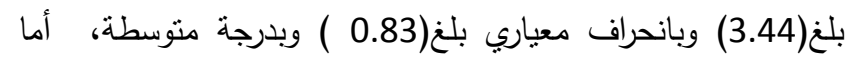

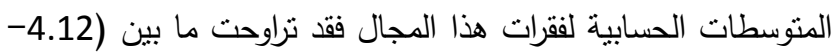

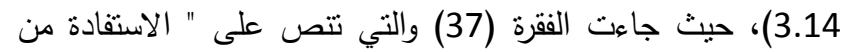

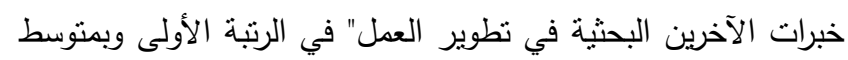

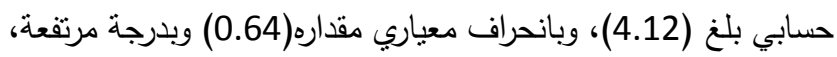
بينما جاءت الفقرة (35) ونصها " إجراء الأبحاث النطبيقية التي تسهم في تطوير العمل" بالمرتبة الأخيرة وبمنوسط حسابي بلغ (3.14) وبانحراف معياري مقداره (0.63) وبدرجة منوسطة، وبلغ المتوسط

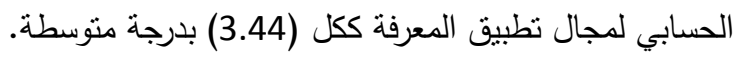
الجدول (6): المتوسطات الحسابية والانحرافات المعيارية لدرجة تطبيق القادة الأكاديميين والإداريين في جامعة آل البيت لإدارة المعرفة من وجهة نظر العاملين فيها حسب متغيرات الجنس والمؤهل العلمي وسنوات الخبرة والمسمى الوظيفي.

\begin{tabular}{|c|c|c|c|c|c|c|c|}
\hline الكلي & تطبيق المعرفة & التشارك في & توليد & تنظيم المعرفة & & الفئات & المتغير \\
\hline 3.66 & 3.64 & 3.63 & 3.61 & 3.75 & س & \multirow[t]{2}{*}{ ذكور } & \multirow{4}{*}{ الجنس } \\
\hline 0.72 & 0.72 & 0.84 & 3.85 & 0.76 & $\varepsilon$ & & \\
\hline 3.34 & 3.42 & 3.18 & 3.26 & 3.47 & س & \multirow[t]{2}{*}{ اناث } & \\
\hline 0.90 & 0.99 & 1.08 & 1.02 & 0.99 & $\varepsilon$ & & \\
\hline 3.56 & 3.60 & 3.51 & 3.47 & 3.65 & س & \multirow{2}{*}{ بكالوريوس } & \multirow{4}{*}{ العلمي المؤل } \\
\hline 0.85 & 0.91 & 0.95 & 0.99 & 0.89 & $\varepsilon$ & & \\
\hline 3.37 & 3.38 & 3.18 & 3.33 & 3.52 & س & \multirow{2}{*}{ دراسات عليا } & \\
\hline 0.78 & 0.89 & 1.05 & 0.89 & 0.90 & $\varepsilon$ & & \\
\hline 3.49 & 3.50 & 3.27 & 3.46 & 3.67 & س & \multirow[t]{2}{*}{ أقل من 5 سنوات } & \multirow{6}{*}{ سنوات الخبرة } \\
\hline 0.72 & 0.89 & 0.93 & 0.86 & 0.84 & $\varepsilon$ & & \\
\hline 3.39 & 3.41 & 3.25 & 3.34 & 3.52 & س & \multirow{2}{*}{ من 5سنوات إلى من 10 من } & \\
\hline 0.72 & 0.88 & 0.99 & 0.96 & 0.87 & $\varepsilon$ & & \\
\hline 3.59 & 3.64 & 3.59 & 3.49 & 3.65 & س & \multirow{2}{*}{ 10سنورت } & \\
\hline 0.90 & 0.94 & 1.00 & 1.00 & 0.95 & $\varepsilon$ & & \\
\hline 3.52 & 3.55 & 3.43 & 3.45 & 3.62 & س & \multirow[t]{2}{*}{ أكاديمي } & \multirow{4}{*}{ الوظيفي } \\
\hline 0.84 & 0.94 & 1.02 & 0.95 & 0.87 & $\varepsilon$ & & \\
\hline 3.54 & 3.49 & 3.35 & 3.39 & 3.57 & س & \multirow[t]{2}{*}{ إداري } & \\
\hline 0.81 & 0.86 & 0.96 & 0.97 & 0.94 & $\varepsilon$ & & \\
\hline
\end{tabular}


وسنوات الخبرة (أقل من 5سنوات)( 5-أقل من 10سنوات) ( 10 يبين الجـول(6) وجـود فـروق ظاهريـة بـين الكتوسـات الحسـابية سـوات فـأكثر ) والمرحلـة التعليميـة (أكـاديمي - إداري). ولبيـان دلالــة

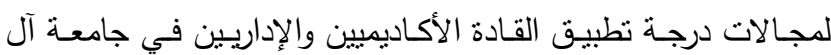
الفروق الإحصائية بين المتوسطات الحسابية تم استخدام تحليل التباين

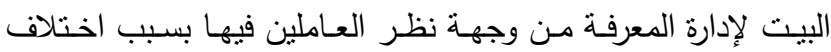
الرباعي والجدول (7) يوضح ذلك.

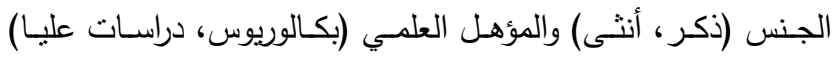
الجدول (7): نتائج نحليل التباين الرباعي لأثر الجنس والمؤهل العلمي وسنوات الخبرة والمسمى الوظيفي لدرجة تطبيق القادة الأكاديميين والإداريين في جامعة آل البيت لإدارة المعرفة من وجهة نظر العاملين فيها.

\begin{tabular}{|c|c|c|c|c|c|c|}
\hline الإحصائية & قيمة ف & المريعات & الحرية & مجموع المريعات & المجالات & مصدر التباين \\
\hline$* 0.00$ & 10.203 & 8.121 & 1 & 8.121 & تنظيم المعرفة & \multirow{5}{*}{ 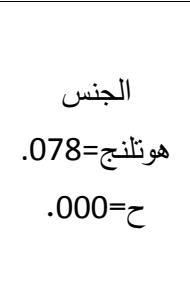 } \\
\hline$* 0.00$ & 14.166 & 12.672 & 1 & 12.672 & توليد المعرفة & \\
\hline$* 0.00$ & 26.587 & 23.870 & 1 & 23.870 & التتشارك في المعرفة & \\
\hline$* 0.00$ & 7.427 & 6.035 & 1 & 6.035 & نطبيق المعرفة & \\
\hline$* 0.00$ & 17.065 & 11.271 & 1 & 11.271 & الدرجة الكلية & \\
\hline 0.29 & 1.145 & 0.911 & 1 & 0.911 & تنظيم المعرفة & \multirow{5}{*}{ هوتلنج=030. } \\
\hline 0.26 & 1.258 & 1.126 & 1 & 1.126 & توليد المعرفة & \\
\hline$* 0.00$ & 8.525 & 7.654 & 1 & 7.654 & التشارك في المعرفة & \\
\hline$* 0.04$ & 4.159 & 3,379 & 1 & 3.379 & تطبيق المعرفة & \\
\hline 0.07 & 3.414 & 2.255 & 1 & 2.255 & الدرجة الكلية & \\
\hline 0.25 & 1.393 & 1.109 & 2 & 2.217 & تتظيم المعرفة & \multirow{5}{*}{ سنوات الخبرة } \\
\hline 0.19 & 1.667 & 1.491 & 2 & 2.982 & توليد المعرفة & \\
\hline$* 0.00$ & 8.950 & 8.035 & 2 & 16.070 & التشارك في المعرفة & \\
\hline$* 0.03$ & 3.512 & 2.854 & 2 & 5.708 & تطبيق المعرفة & \\
\hline 0.93 & 3.493 & 2.307 & 2 & 4.614 & الدرجة الكلية & \\
\hline 0.82 & 0.055 & 0.044 & 1 & 0.044 & تنظيم المعرفة & \multirow{5}{*}{ المسمى الوظيفي } \\
\hline 0.71 & 0.143 & 0.128 & 1 & 0.128 & نوليد المعرفة & \\
\hline 0.55 & 0.354 & 0.318 & 1 & 0.318 & التشارك في المعرفة & \\
\hline 0.67 & 0.178 & 0.145 & 1 & 0.145 & تطبيق المعرفة & \\
\hline \multirow[t]{11}{*}{0.66} & 0.193 & 0.127 & 1 & 0.127 & الدرجة الكلية & \\
\hline & & 0.796 & 369 & 293.711 & تنظيم المعرفة & \multirow{5}{*}{ الخطأ } \\
\hline & & 0.895 & 369 & 330.088 & توليد المعرفة & \\
\hline & & 0.898 & 369 & 331.293 & التشارك في المعرفة & \\
\hline & & 0.812 & 369 & 299.808 & تطبيق المعرفة & \\
\hline & & 0.660 & 369 & 243.722 & الدرجة الكلية & \\
\hline & & & 375 & 5189.969 & تنظيم المعرفة & \multirow{5}{*}{ الكلي } \\
\hline & & & 375 & 4760.136 & توليد المعرفة & \\
\hline & & & 375 & 4712.120 & التشارك في المعرفة & \\
\hline & & & 375 & 4987.472 & تطبيق المعرفة & \\
\hline & & & 375 & 4848.767 & الدرجة الكلية & \\
\hline
\end{tabular}

لمتغيـر الجنس وجـاءت الفـروق لصـالح الـكور وذلك في جميـع

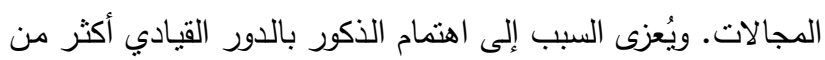

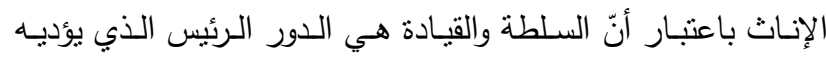

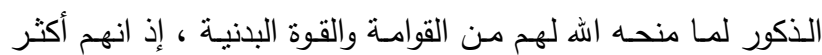

* ذات دلالة إحصائية عند مستوى دلالة ( 0.05 ) يبين الجدول (7) الآتي:

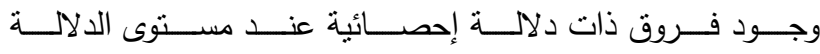

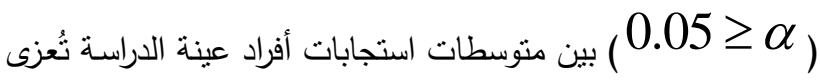


الذين يطحسون للحراك الوظيفي إلى الأعلى بينما دلت عدم وجود فروق في مجالي تتظيم المعرفة وتوليد المعرفة. وتُعزى هذه النتيجة التحان

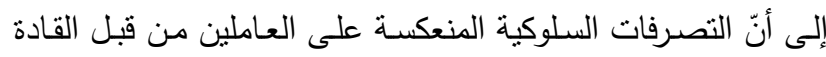

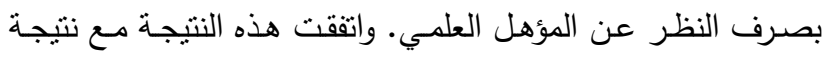

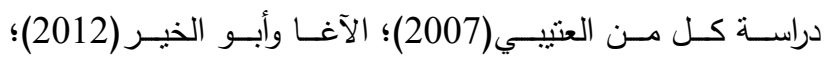

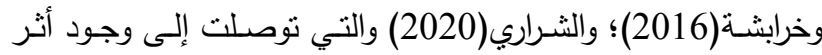

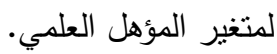

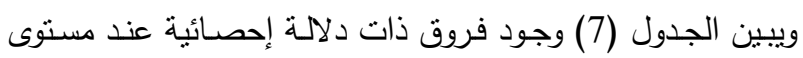

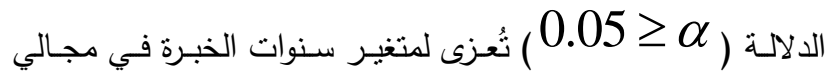
التشارك في المعرفة وتطبيق المعرفة ، ولمعرفة الفرق من بين سنوات

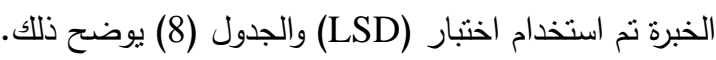

تحملاً لأعباء الإدارة. واتفقت هذه النتيجة مع نتيجة دراسة كل من الزبون والثيخ(2015)؛ خرابشـة(2016)؛ والتي توصلت إلى وجود

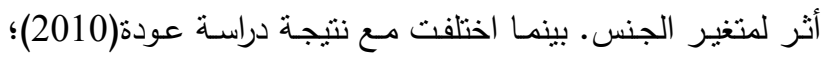
والمنصوري(2011)؛ والطحاينة والخالدي(2015)؛ والثراري(2020) والعدوان وطناش(2020)؛ وصلاح والفارسية(2021) والتي نوصلت إلى عدم وجود أثر لمتغير الجنس.

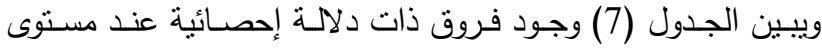

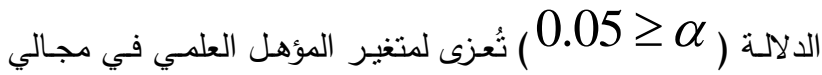
التثارك في المعرفة وتطبيق المعرفة ، وجاءت الفروق لصالح المؤهل (البكالوريوس) ، وقد تُعزى هذه النتيجة لوجود النشاط والحماسة في العمل لديهم إذ يميلون للاستقرار أكثر من أصحاب الدراسات العليا

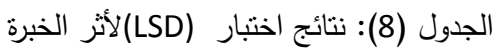

\begin{tabular}{|c|c|c|c|c|}
\hline 10سنوات -فأكثر & من 5-أقل من 10سنوات & أقل من5 سنوات & المستوى & المجال \\
\hline$* .017$ & .88 & - & أقل من 5سنوات & \multirow{3}{*}{ المعرفة } \\
\hline${ }^{*} 0.02$ & - & .88 & من 5-أقل من 10سنوات & \\
\hline - & $* .002$ & *.017 & 10سنوات-فأكثر & \\
\hline .24 & 49 & - & أقل من 5سنوات & \multirow{3}{*}{ تطبيق } \\
\hline$* .025$ & - & 49 & من 5-أقل من 10سنوات & \\
\hline- & .025 & .243 & 10سنوات-فأكثر & \\
\hline
\end{tabular}

والخالـــدي(2015)؛ خرابشـــــ(2016)؛ صــــالح(2017)؛ والثراري(2020) التي توصلت إلى عدم وجود أثر لـتغير سنوات

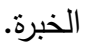

ويبين الجدول (8) عدم وجود فروق ذات دلالة إحصائية عند مستوى

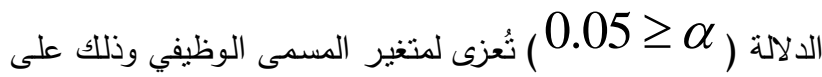

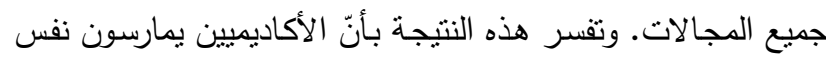

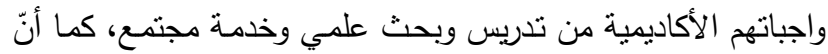
العاملين الإداريين يمارسون صـاحياتهم بموجب الوصف الوظيفي لديهم لذا جاءت النتائج منماثلة بين الأكاديميين والإداريين دون وجود الإدين

بناءً على النتائج التي توصلت إليها الدراسة، يوصي الباحثان بالآتي: 1- العمل على تقليص الفجوات والعقبات التي تعرقل تطبيق

إدارة المعرفة وضرورة إيجاد الحلول المناسبة لها. 2- نوفير كافة الإمكانات المتاحة لزيادة المقدرات والمهارات الإبداعية لدى القادة الأكاديميين والإداريين وتحفيزهم التقديم

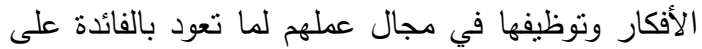

يوضـح الجدول (8) وجود فروق ذات دلالـة إحصـائية عند مستوى

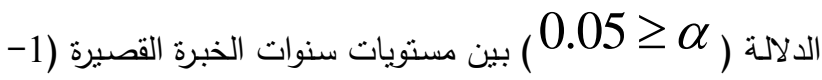
أقل من 5) والمنوسطة من( 5-أقل من 10) والطويلة (10_فأكثر) على مجالي الاستتارة الفكرية والاعتبارية الفردية حيث كانت الفروق

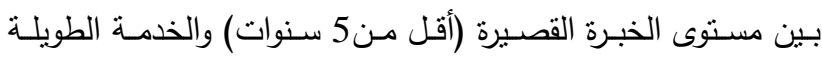

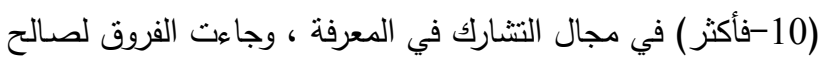
سنوات الخبرة الطويلة وتُعزى هذه النتيجة إلى فهم وتعدق العاملين لعملهم والوصول لدرجة عالية من النضج الوظيفي. بينما في مجال تطبيق المعرفـة هنالك فروق بين سنوات الخبرة المتوسطة (5-أقل

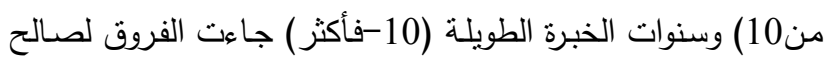

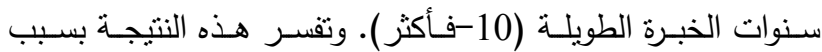

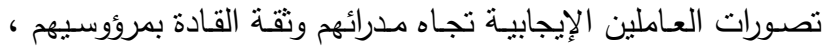
ووصــول العـاملين ذوي الخبـرة الطويلـة إلـى النهـو المهنــي الأكثر

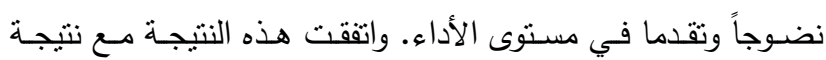

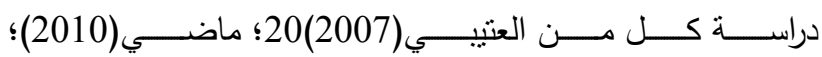

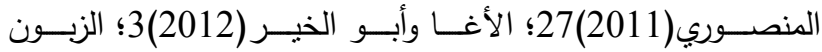
والثـيخ(11)؛ التي نوصـلت إلى وجود أثر لمتغير سـوات

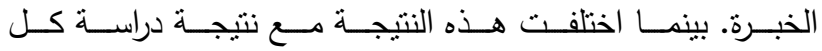

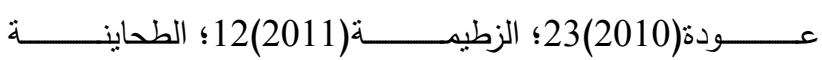


7. Al-Harthy, Ghazi and Al-Faydi, Acer, The role of knowledge management in project management. The Eleventh International Scientific Conference, entitled "The Role of Human, Social and Natural Sciences in Supporting Sustainable Development" December 9-10, 2020 - Istanbul - Turkey, 2020

8. Kharabsheh, Omar , The degree of application of knowledge management at Al-Balqa Applied University in Jordan from the point of view of its faculty members, Studies, Educational Sciences, 43 (Supplement 5): 1829-1853, 2016

9. Khreisat, Islam, The basic components of knowledge management in Jordanian universities and building a proposed model for those components, unpublished master's thesis, Al-Balqa Applied University, Amman, Jordan, 2018

10. Al-Rashidi, Nayef, "The Role of Knowledge Management in Achieving Quality Education in Educational Institutions in the State of Kuwait, The Arab Journal of Literature and Human Studies, 4(15): 355-382, 2020

11. Customer, Muhammad and Sheikh, Manal, The reality of knowledge management in private Jordanian universities from the viewpoint of faculty members and its relationship to some variables, Studies, Educational Sciences, 42(2): 461- 480, 2015

12. Al-Zatma, Nidal, "Knowledge management and its impact on performance excellence, an applied study on colleges and intermediate technical institutes operating in the Gaza Strip." Unpublished Master's Thesis, The Islamic University, Gaza, Palestine. Available at the following link: http://library.iugaza.edu.ps/thesis/ Date of entry $12 / 14 / 2019$.

13. Sabrina, Manea and Bouzidi, Huda , "Applications of knowledge management in institutions of higher education and scientific research" Analytical reading of the experiences of some countries, The Economic Researcher Journal, 6 (10): 249270, 2018

14. Al-Suhaimi, Zainab, Readiness of organizations for knowledge management: an applied case: King Abdulaziz University in Jeddah. International Conference on Administrative Development towards Distinguished Performance in the Governmental Sector, Riyadh: Institute of Public Administration, 2009

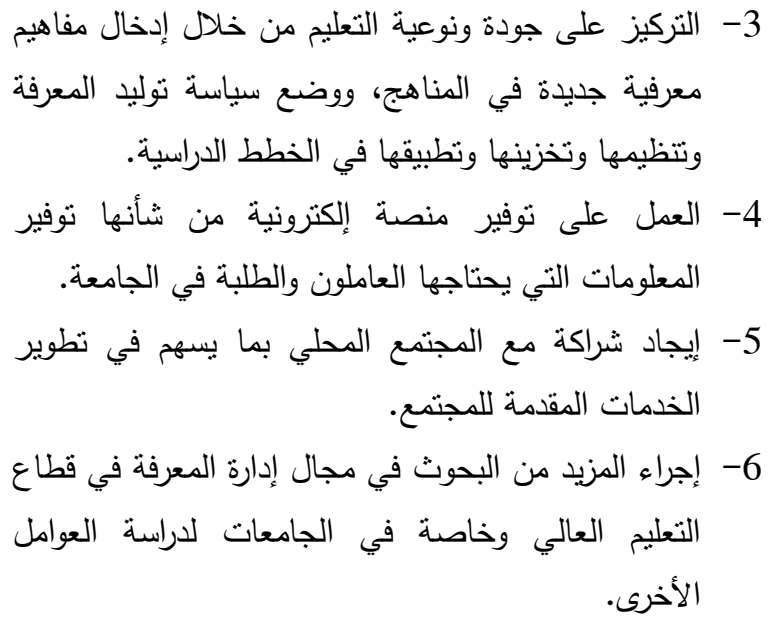

References:

1. Abu Al-Nadi, Maram, Suggested rules for knowledge management in public Jordanian universities based on selected models. Unpublished $\mathrm{PhD}$ thesis, University of Jordan, Amman, Jordan, 2009

2. Abu Khdeir, Iman , Knowledge management applications in higher education institutions: ideas and practices. International Conference on Administrative Development towards Distinguished Performance in the Governmental Sector, Riyadh: Institute of Public Administration, 2009

3. Al-Agha, Nasser and Abu Al-Khair, Ahmed, The reality of the application of knowledge management processes at Al-Quds Open University and the procedures for its development, Al-Aqsa University Journal (Human Sciences Series), 16 (1):30-62, 2012

4. Barakat, Ziyad and Awad, Ahmed, The reality of the role of Arab universities in the development of the knowledge society from the point of view of a sample of its faculty members. Journal of the Association of Arab Universities, General Secretariat of the Association of Arab Universities, (56): 71113, 2011

5. Barhouma, Samir , Characteristics of entrepreneurship and its impact on entrepreneurial projects: an applied study on students of business incubators in Jordanian universities, unpublished $\mathrm{PhD}$ thesis, International Islamic Sciences University, Amman, Jordan, 2014

6. Al-Talbani, Nihaya and Badir, Ramez and Al-Raqab, Muhammad , Requirements for the application of knowledge management in Palestinian universities in the Gaza Strip, the Jordanian Journal of Business Administration, 11(2):443-480, 2015 
24. Al-Kubaisi, Salah al-Din, Knowledge Management, Cairo: Arab Administrative Development Organization, 2011

25. Madi, Ismail , "The role of knowledge management in ensuring the quality of higher education is a case study of the Islamic University of Gaza", unpublished master's thesis, The Islamic University, Gaza, Palestine, 2010

26. Al-Muhaimid, Nasser, Professional Project Management PMI, Riyadh: King Fahd National Library, 2017

27. Al-Mansoori, Ahmed, The degree of application of knowledge management processes at Sultan Qaboos University in the Sultanate of Oman from the point of view of its faculty members, unpublished master's thesis, Yarmouk University, Irbid, Jordan, 2011

28. Momani, Hassan , Attitudes of managers towards the application of knowledge management in public institutions in Jordan. Unpublished master's thesis, Mafraq: Al alBayt University, 2005

29. Al-Najjar, Adel, A proposed educational leadership model for secondary school principals, to raise the professional performance of teachers in the light of knowledge management in Jordan. Unpublished doctoral thesis, University of Jordan, Amman, Jordan, 2013.

30. Brewer, P.; Brewer, K, "Knowledge Management, Human Resource Management, and Higher Education: A Theoretical Model", Journal of Education for Business,.85(6),.330-335,2010.

31. Coukos , S, D, Knowledge Management Processes and Strategies Use in United States Research universities. Dissertation Abstracts International., 2002

32. Lee, H. \& Choi, B, "Knowledge enablers, processes and organizational performance: An integrated view and empirical examination", Journal of Management Information Systems, pp. 179-228, 2003.

33. Mikulecka, J. \& Mikulecky, P," University knowledge management issues and prospects", Principles of Data Mining and Knowledge Discovery 4th European Conference Proceedings, PKDD, Lyon, France, P.P.157- 165, 2000.

34. Nurluoz,O.; Birol,C., "The Impact of Knowledge Management and Technology: An Analysis of Administrative Behaviours",
15. Al-Sharari, Sherif, The extent to which science teachers practice knowledge management processes from their point of view in Qurayyat Education Department, International Journal of Educational and Psychological Studies, 7(1): 171-188, 2020

16. Saleh, Hanin, The degree of employment of knowledge management among academic leaders in Jordanian universities in light of the dimensions of the educated institution from the point of view of faculty members, unpublished master's thesis, Middle East University, Amman, Jordan, 2017

17. Salah El-Din, Nasreen and Al-Farsi, Badria, The degree of availability and importance of the requirements for the application of knowledge management in educational supervision from the point of view of supervisors in the Sultanate of Oman, International Journal of Educational and Psychological Studies, 9(3): 858-878, 2021

18. Tahaineh, Ziyad and Al-Khalidi, Hassan , The application of knowledge management processes in the faculties of physical education in Jordanian universities, Studies Educational Sciences, 42(2):571-585, 2015

19. Al-Abadi, Hashem and Al-Tai, Youssef and Al-Asadi, Afnan , University education management, a modern concept in contemporary administrative thought. Amman: Al-Warraq Publishing and Distribution Corporation, 2008

20. Al-Otaibi, Yasser, "Knowledge management and the possibility of its application in Saudi universities: an applied study on Umm Al-Qura University", unpublished $\mathrm{PhD}$ thesis, College of Education, Umm Al-Qura University, Makkah Al-Mukarramah, 2007

21. Al-Adwan, Hussein and Watanash, Salama, The reality of the role of knowledge management in building the learning organization at the University of Jordan from the point of view of academic leaders and faculty members, The Jordanian Educational Journal, 5(3): 239-263, 2020

22. Al-Ali, Abdul-Sattar, Kandilji, Amer, and Al-Omari, Ghassan , Introduction to knowledge management. Amman: Dar Al Masirah for publishing, distribution and printing, 2006

23. Odeh, Firas, The reality of knowledge management in Palestinian universities and ways to support it, unpublished master's thesis, the Islamic University, Gaza, 2010 
TheTurkish Online Journal of Educational Technology, Jan.,(.10),. 202-208, 2011

35. Ralph, L, An Investigation of Knowledge Management Solution, A dissertation, Southeasten. University, 2008 